\title{
Antimicrobial Activity, In Vitro Anticancer Effect (MCF7 Breast Cancer Cell Line), Antiangiogenic and Immunomodulatory Potentials of Populus Nigra L. Buds Extract
}

\section{Brigitta Kis}

Department of Pharmacognosy, "Victor Babeș" University of Medicine and Pharmacy Timișoara, Romania, Eftimie Murgu Sq. no. 2, 300041

Timișoara

loana Zinuca Pavel ( $\square$ ioanaz.pavel@umft.ro)

Department of Pharmacognosy, "Victor Babeș" University of Medicine and Pharmacy Timișoara, Romania, Eftimie Murgu Sq. no. 2, 300041

Timișoara

\section{Stefana Avram}

Department of Pharmacognosy, "Victor Babeș" University of Medicine and Pharmacy Timișoara, Romania, Eftimie Murgu Sq. no. 2, 300041

Timișoara

\section{Elena Alina Moaca}

Department of Toxicology, "Victor Babeș" University of Medicine and Pharmacy Timișoara, Romania, Eftimie Murgu Sq. no. 2, 300041 Timișoara

Martina Herrero San Juan

Pharmazentrum frankfurt/ZAFES, Institute of General Pharmacology and Toxicology, Hospital of the Goethe University, D-60590 Frankfurt/Main

Anja Schwiebs

Pharmazentrum frankfurt/ZAFES, Institute of General Pharmacology and Toxicology, Hospital of the Goethe University, D-60590 Frankfurt/Main

Heinfried H. Radeke

Pharmazentrum frankfurt/ZAFES, Institute of General Pharmacology and Toxicology, Hospital of the Goethe University, D-60590 Frankfurt/Main

\section{Delia Muntean}

Department of Microbiology, "Victor Babeș" University of Medicine and Pharmacy Timișoara, Romania, Eftimie Murgu Sq. no. 2, 300041

Timișoara

\section{Zorita Diaconeasa}

Department of Food Science and Technology, Faculty of Food Science and Technology, University of Agricultural Science and Veterinary

Medicine, Calea Manastur, 3-5, 400372 Cluj-Napoca

\section{Daliana Minda}

Department of Pharmacognosy, "Victor Babeș" University of Medicine and Pharmacy Timișoara, Romania, Eftimie Murgu Sq. no. 2, 300041

Timișoara

\section{Camelia Oprean}

Department of Pharmacy I, Drug Analysis, "Victor Babeș" University of Medicine and Pharmacy Timișoara, Romania, Eftimie Murgu Sq. no. 2, 300041 Timișoara

\section{Florina Bojin}

“Pius Brinzeu” Timişoara County Emergency Clinical Hospital, Oncogen Institute, 156 Liviu Rebreanu, 300723, Timişoara

\section{Cristina Adriana Dehelean}

Department of Toxicology, "Victor Babeș" University of Medicine and Pharmacy Timișoara, Romania, Eftimie Murgu Sq. no. 2, 300041 Timișoara

\section{Codruta Soica}

Department of Pharmaceutical Chemistry, "Victor Babeș" University of Medicine and Pharmacy Timișoara, Romania, Eftimie Murgu Sq. no. 2,

300041 Timișoara

\section{Corina Danciu}

Department of Pharmacognosy, "Victor Babeș" University of Medicine and Pharmacy Timișoara, Romania, Eftimie Murgu Sq. no. 2, 300041

Timișoara

\section{Research Article}

Keywords: Populus nigra L. buds, antibacterial, MCF7 breast cancer cell line, chorioallantoic membrane, dendritic cells.

Posted Date: October 6th, 2021 
DOI: https://doi.org/10.21203/rs.3.rs-737416/v1

License: (c) (i) This work is licensed under a Creative Commons Attribution 4.0 International License. Read Full License 


\section{Abstract}

Purpose: The aim of this study was to evaluate the antioxidant potential, antimicrobial activity, the in vitro anticancer effect (MCF7 breast cancer cell line), as well as the antiangiogenic and immunomodulatory potential of Populus nigra L. bud (Pg) extract collected from the western part of Romania.

Results:Populus nigra L. bud extract presents an important antioxidant activity, due to the rich phytochemical composition. Regarding the biological activity, results have shown that poplar bud extract presents a significant inhibitory activity against Gram-positive bacteria and a dosedependent decrease of MCF7 tumor cell viability with an $\mathrm{IC}_{50}$ of $66.26 \mu \mathrm{g} / \mathrm{mL}$, while not affecting healthy cells. Phenomena of early apoptotic events at the maximum concentration tested $(150 \mu \mathrm{g} / \mathrm{mL})$ were detected by Annexin V-PI double staining. The extract induced G0/G1 phase cell cycle arrest. In addition, Pg extract showed antiangiogenic potential on the chorioallantoic membrane. Also, at the highest concentration (150 $\mu \mathrm{g} / \mathrm{mL}$ ), good tolerability and no signs of toxicity upon vascular plexus were observed. Moreover, in low concentrations, the Pg extract had immunomodulatory activity on primary human dendritic cells by upregulating IL-12 and IL-23 subunits.

Conclusion:The study concludes that poplar bud extract elicited antioxidant activity, antitumor properties on the breast cancer cell line, followed by an antiangiogenic effect and an immunomodulatory potential on human primary dendritic cells. The biological activity of Populus nigra L. buds extract may open new directions of research on the topic addressed.

\section{Background}

Populus nigra L. (black poplar) belongs to the Salicaceae family, widespread especially in Europe and Asia. In Romania it grows through meadows and wetlands but can also occur in plains. Currently in therapy, the most used part of the tree are the foliar buds, due to the complex phytochemical composition responsible for a wide range of therapeutic activities. Poplar buds are described as conical, elongated, measuring $2 \mathrm{~cm}$ long and $5-8$ $\mathrm{mm}$ thick, with a sharp and slightly curved tip. Poplar buds are covered with a sticky and shiny resin, having a weak balsamic and aromatic smell. On the central axis of the buds are 4-8 oval and sharp bracts, adherent due to the resins in the composition $[1,2]$.

Flavonoid derivatives are currently described as one of the main phytochemicals in poplar buds. They are represented by flavones (chrysol, tectocrizol, apigenol), flavonols (galangin, kaempferol, quercetol), flavanones (pinocembrin, pinostrobin). Also, phenolic acids and their esters, such as caffeic acid, p-coumaric, isoferulic (over 17 different esters) are listed among the main phytochemicals detected in different poplar bud extracts. Beside the flavonoid derivatives and phenolic acids, extracts obtained from poplar buds represent a source of phenolic heterosides namely, populoside (the benzoic ester of salicoside) and salicoside [3,4]. Different phytochemical studies have also reported the presence of other components in the composition of poplar bud extract. These phytochemicals include tannins, waxes, resins, glucose, fructose, oligosaccharides, triterpene derivatives ( $\alpha$ and $\beta$ amirenol) $[5,6]$. Essential oils as well, mainly rich in cadinen, cineol, bisabolol, humulin, farnesol, bisabolene, have also been reported as important components of black poplar bud extracts [7].

Poplar buds have been assigned with a wide range of properties both in folk and evidence-based medicine. Black poplar extracts have shown promising effects on patients with respiratory conditions, such as bronchitis, asthma, laryngitis, sore throat, and flu [8] due to expectorant, antimicrobial, anti-inflammatory, analgesic, anti-rheumatic, astringent, antioxidant and capillary-protective effects [9, 10]. In order to benefit from the maximum concentration of active principles, the harvest of the vegetal product is carried out in March-April, before the development of the leaves [11]. The resins from black poplar buds represents an important source of propolis [12]. An increased number of studies have proven that black poplar bud extracts represent a source of polyphenolic compounds responsible for its strong antioxidant properties. Moreover, literature describes studies which detail the antibacterial and antifungal activities of poplar bud extracts [13].

In addition, extracts obtained from this vegetal product present significant anti-inflammatory activity which is attributed to the high number of flavonoids (e.g. pinocembrin, quercetin). Pobłocka-Olech et al. demonstrated that 20-40 $\mu \mathrm{M}$ of ethanolic poplar bud extract (Poland), significantly reduces the pro-inflammatory interleukins (IL-1 $\beta$ and IL-6) in vitro using HGF-1 cell lines [14]. Wang K. et al, described the effects of ethanolic extract of Populus $x$ canadensis buds (China), in vivo on acute inflammatory symptoms (animal male ICR mice strain induced with acute pulmonary damage and lipopolysaccharide (LPS) induced endotoxemia). The extract (25, $100 \mathrm{mg} / \mathrm{kg})$ presented significant anti-inflammatory effects mainly by inhibiting the production of inflammatory cytokines such as IL-6, IL-10, tumor necrosis factor-a (TNF-a) and blocking nuclear factor (NF)-кB [15]. Regarding the antitumor properties, literature is poor in studies that report this kind of activity. However, there are many phytochemicals which can be found in black poplar bud extracts which have been assigned with antitumoral effects (e.g. pinocembrin, chrysin, pinostrobin).

The aim of this study was to conduct a phytochemical characterization of black poplar bud extract obtained from the western areas of Romania, including the phenolic content, antioxidant screening along with a biological evaluation in terms of antimicrobial activity, in vitro anticancer effect (MCF7 breast cancer cell line), and immunomodulatory potential and an in vivo antiangiogenic effect.

\section{Materials And Methods}




\section{Plant materials and reagents}

Poplar buds were collected from the west part of Romania (Timisoara) by a student of the Victor Babes University of Medicine and Pharmacy, identified in the department of Pharmacognosy, and assigned the voucher specimen code Pg 3/2019. The extraction procedure was as follows: 10 $\mathrm{g}$ of dried and grounded vegetable product was mixed with $100 \mathrm{~mL}$ of $70 \%$ ethanol and covered with parafilm. After 10 minutes at room temperature the extract was ultrasonicated for 30 minutes at the temperature of $50^{\circ} \mathrm{C}$ and frequency of $40 \mathrm{KHz}$ (FALC LBS 2 ultrasonic water bath). The extract was afterwards filtered through filter paper by the help of a vacuum pump (Vacuubrand). In order to eliminate the solvent, a rotary evaporator (HEIDOLPH Laborata 4000 efficient WB eco) was used at $50^{\circ} \mathrm{C}$, under reduced pressure. For better drying the extract was placed in an etuve (Genlab N40 C) at $50^{\circ} \mathrm{C}$ for $5-6$ hours. The extract (called on further in the paper- $\mathrm{Pg}$ ) was subsequently stored at $-4^{\circ} \mathrm{C}$ until use [10].

\section{Antioxidant activity- Radical scavenging activity}

In order to evaluate the AOA, the DPPH (2,2-diphenyl-1-picrylhydrazyl, Sigma Aldrich, Germany) assay was employed. Based on the method of Manzocco et al. [16] and modified by our research group [17] the DPPH assay implies the oxido-reduction reaction between the standard oxidant (DPPH radical) and the antioxidants from the analyzed sample. The chemical reaction is considered to be finished after the change color occurs in the mixture (from intense purple to pale yellow). Basically, an exact amount of DPPH in ethanol solution (1 mM) was mixed with each concentration of hydro-alcoholic Pg extract and analyzed 1200 seconds in order to evaluate the kinetic of the reaction, using a T70 UV/VIS Spectrophotometer, from PG Instruments. The absorbance values recorded every 20 seconds, for each hydro-alcoholic extract, were used to determine the antioxidant activity, using the following equation: (1)

Antioxidant activity $[\%]=\left[\left(A_{D P P H}-A_{\text {extract }}\right) \div A_{D P P H}\right\rfloor \times 100$

where: $A_{D P P H}$ - is the absorbance of standard oxidant, without extract, analyzed at $517 \mathrm{~nm}$; and $A_{\text {extract }}$ - is the absorbance of the mixture (extract + $\mathrm{DPPH})$, analyzed at $517 \mathrm{~nm}$. As a standard reference, it was used as a stock $\mathrm{C}$ vitamin ethanolic solution $(400 \mu \mathrm{g} / \mathrm{mL})$. The IC ${ }_{50}$ alongside by $\mathrm{IC}_{10}$, $I_{2}, I_{80}$ and $I C_{90}$, were determined by using OriginPro 2020 software, and the set of data (repeated three times) was fitted using a Nonlinear Curve Growth Sigmoidal model, choosing the function: Dose response curve with variable Hill slope given by parameter " $p$ ".

\section{Physicochemical screening}

In order to characterize the compounds contained in Pg extract, Fourier-transform infrared spectroscopy and thermal analysis were employed.

\section{Fourier-transform infrared spectroscopy - FT-IR}

The FT-IR spectra of each resultant compound were recorded in the range from $4000-400 \mathrm{~cm}^{-1}$ on $\mathrm{KBr}$ pellets, under reduced pressure. A Prestige21 spectrometer (Shimadzu, Duisburg, Germany) operating with a peak resolution of $4 \mathrm{~cm}^{-1}$, at room temperature conditions, was employed to perform the spectra.

Based on the presence of a peak and at a specific wavenumber, FT-IR investigations were employed to identify the functional groups of the main active compounds which are present in the dried Pg extract. FT-IR technique it's a qualitative analysis which can be considered, like HPLC analysis, a chemical fingerprint [18]. The difference between the two analyses is based on the fact that FT-IR is a chemical fingerprint for the functional groups contained by the extract molecules, while the HPLC is a chemical fingerprint for each component contained in the extract. In addition, the HPLC technique quantifies each component after identification.

Thermal analysis

Thermogravimetry-Differential scanning calorimetry (TG-DSC) is an analytical technique which was used to assess the stability and composition of organic compounds contained in dried extract based to Pg, thus predicting biological stability prior to in vitro and in vivo application [19]. TGDSC analysis was performed using a STA 449C instrument (Netzsch, Selb, Germany) in air atmosphere at a flow rate of $20 \mathrm{~mL} / \mathrm{min}$. The curves were recorded in the range $25-1000^{\circ} \mathrm{C}$ with a heating rate of $10 \mathrm{~K} / \mathrm{min}$, using alumina crucibles.

In vitroantimicrobial effects

Another aim of this study was to screen this extract for its antimicrobial properties against eight microorganisms (Thermo Scientific, USA) (Staphylococcus aureus, ATCC code 25923; Streptococcus mutans, ATCC code 35668; Streptococcus pyogenes, ATCC code 19615; Enterococcus faecalis, ATCC code 51299; Escherichia coli, ATCC code 25922; Pseudomonas aeruginosa, ATCC code 27853; Candida albicans, ATCC code 10231; Candida parapsilosis, ATCC code 22019). Were selected these eight strains because they are the most common pathogens responsible for most of the healthcare problems. The susceptibility of microorganisms to the tested compounds was determined using disk diffusion method and dilution

Page $4 / 27$ 
method, according to the European Committee on Antimicrobial Susceptibility Testing (EUCAST), Clinical Laboratory and Standard Institute (CLSI) and based on previous similar studies $[20,21]$.

Disk diffusion method

The antimicrobial activity of the extract was evaluated by the agar disk diffusion method, as previously described [22, 23]. The standardized suspension was prepared in normal saline to a concentration of $0.5 \mathrm{McFarland}$. The un-supplemented Mueller Hinton (MH) agar with $5 \%$ defibrinated horse blood and $\beta$-NAD (MH-F) was inoculated with $100 \mu \mathrm{L}$ of this suspension. Were added $10 \mu \mathrm{L}$ from each sample to a 6 mm

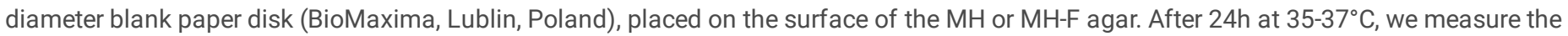
inhibition areas in millimeters. For all microbial strains these assays were done in triplicate and the average values were registered. The antibacterial activity of this extract was established according to the standardized value of the positive control, for gentamycin a diameter of the inhibition area $\geq 15 \mathrm{~mm}$ was considered as susceptibility, while for fluconazole the diameter was $\geq 19 \mathrm{~mm}$. For negative control, were used a disk impregnated only with DMSO.

Dilution method

Standardized suspension was adjusted, by dilution, obtaining a microbial suspension of approximately $10^{5}$ colony forming units (CFU)/mL. For each compound tested, serial dilutions were prepared in MH-F broth: 5, 2.5, 1.25, 0.625, 0.312, $0.156 \mathrm{mg} / \mathrm{mL}$. One milliliter from each dilution of tested compound and $1 \mathrm{~mL}$ inoculum were added in six test tubes, to a final microbial suspension of $0.5 \times 10^{5} \mathrm{CFU} / \mathrm{mL}$ and a final compound dilution between 2.5 and $0.078 \mathrm{mg} / \mathrm{mL}$. After incubating at $37^{\circ} \mathrm{C}$ for $24 \mathrm{~h}$, the MIC was analyzed. To determine the MBC a volume of $1 \mu \mathrm{l}$ from the test tubes with no visible growth was inoculated on Columbia agar supplemented with $5 \%$ blood. After incubation at $37^{\circ} \mathrm{C}$ for $24 \mathrm{~h}$, the lowest concentration that kills $99.9 \%$ of the microorganisms was established [21].

\section{Cell culture and cell preparation}

The MCF7 human breast adenocarcinoma (ATCC ${ }^{\circledR}$ HTB-22 ${ }^{\mathrm{TM}}$ ) was purchased from the American Type Culture Collection (ATCC). MCF7 cells were cultured in RPMI-1640 medium (ATCC $\AA 30-2001^{\mathrm{TM}}$ ). The cell line was supplemented with $10 \%$ fetal bovine serum (FBS; Sigma-Aldrich, Germany) and $1 \%$ penicillin/streptomycin mixture (Pen/Strep, 10,000 IU/mL; Sigma-Aldrich, Germany). The cells were maintained in standard conditions (humidified atmosphere with $5 \% \mathrm{CO}_{2}$ and $37^{\circ} \mathrm{C}$ ). Human Dendritic cells were differentiated from isolated PBMCs from buffy coats according to

Nair et al. [24]. In brief, density centrifugation was performed using Ficoll (GE Healthcare, Uppsala, Sweden). Isolated PBMCs have been plated in 6well plates and supernatant has been discarded upon $2 \mathrm{~h}$ of plastic adherence. Subsequently, cells were differentiated in RPMI 1640 GlutaMax medium (Thermo Fisher Scientific, Massachusetts, USA) supplemented with 10\% autologous serum, $100 \mathrm{IU} / \mathrm{ml}$ penicillin, $100 \mu \mathrm{g} / \mathrm{ml}$ streptomycin, $10 \mathrm{mM}$ HEPES (Sigma-Aldrich, Steinheim, Germany), $1 \mathrm{mM}$ sodium pyruvate and $50 \mu \mathrm{M}$ 2- $\beta$-ME (Thermo Fisher Scientific, Massachusetts, USA) supplemented with $40 \mathrm{ng} / \mathrm{ml}$ recombinant human GM-CSF (Peprotech, NJ, USA) and human IL4 (Peprotech, NJ, USA) for 6 days. Differentiated cells were stimulated with the Pg extract in different concentrations (1-100 $\mu \mathrm{g} / \mathrm{ml})$ or $1 \%$ DMSO as a control. In parallel, $250 \mathrm{nM}$ LPS stimulation was used to generate inflammatory dendritic cells. After stimulation, cells were harvested by cell scraping for further analysis and supernatant has been collected and snapfrozen for further analysis.

\section{Anticancer activity}

Antiproliferative MTT assay

The Pg extract was evaluated for possible in vitro anticancer activity against the MCF7 human breast cancer cell line. The effect of black poplar bud extracts on MCF7 breast cancer cells viability was evaluated by means of MTT (3-(4,5-dimethylthiazol-2-yl)-2,5-diphenyltetrazolium bromide) assay. The method was conducted as previously described [25]. Briefly, $1 \times 10^{4}$ cells/well were seeded in 96-well culture plates and allowed to adhere overnight. On the second day, the cells were stimulated with different concentrations of poplar bud extracts (10, 25, 50, 75, 100 and 150 $\mu \mathrm{g} / \mathrm{mL}$ ) and were incubated for $72 \mathrm{~h}$. The Control group is represented by cells treated with the solvent dimethyl sulfoxide (DMSO, Sigma-Aldrich). After the $72 \mathrm{~h}$ incubation period, the cells were treated with $10 \mu \mathrm{L}$ of $5 \mathrm{mg} / \mathrm{mL}$ MTT solution from the MTT kit (Sigma-Aldrich) and incubated for an additional $3 \mathrm{~h}$. The obtained formazan crystals were dissolved in $100 \mu \mathrm{L}$ of lysis solution provided in the MTT kit. The absorbance was determined at $570 \mathrm{~nm}$ with a microplate reader (BioRad, xMark Microplate Spectrophotometer).

Determination of the cytotoxic potential by Lactate Dehydrogenase (LDH) assay

The cytotoxic effect of Pg on MCF7 tumor cells was determined by LDH assay (Cytotoxicity detection kit, 11644793001, Roche). Briefly, 5x10 3 cells/well were seeded in 96-well culture plates and allowed to adhere overnight. The second day, the cells were stimulated with different concentrations of poplar bud extract $(10,25,50,75,100$ and $150 \mu \mathrm{g} / \mathrm{mL})$ and incubated for $72 \mathrm{~h}$. After the incubation period, $100 \mu \mathrm{L}$ from each well was transferred into a 96-well culture plate and mixed with $100 \mu \mathrm{L}$ of reaction mixture (prepared according to the manufacturer's instructions) and incubated at room temperature for $30 \mathrm{~min}$. The level of LDH release in the medium was measured at $490 \mathrm{~nm}$ and $680 \mathrm{~nm}$ using a microplate 
reader (BioRad, xMark Microplate Spectrophotometer). Untreated cells (low control) and cells treated with 1\% (v/v) Triton- X100 (high control) were used to determine spontaneous and maximum release of LDH, respectively.

Scratch assay

The scratch assay was performed in order for the assessment of the regressive effect of Pg extracts on the invasion capacity of MCF7 breast cancer cells. Several $2 \times 10^{5}$ cells/well were seeded onto 12 -well culture plates until $90 \%$ confluence was reached. After that, the attached cells were scratched following the diameter of the well using a sterile pipette tip. The detached cells and cellular debris were removed by gently washing the wells with Phosphate Buffer Saline (PBS). Furthermore, the cells were stimulated with different concentrations of poplar bud extracts (10, 25, 50, 75,100 and $150 \mu \mathrm{g} / \mathrm{mL}$ ). Wells were captured on images at $0 \mathrm{~h}$ and $24 \mathrm{~h}$, in order to compare the cell growth of the stimulated and the control cells (no stimulation) in early stages and at consistent times. Images were taken with Olympus IX73 inverted microscope provided with DP74 camera (Olympus, Tokyo, Japan) and cellSense Dimension software was used for analyzing the cell growth. The scratch closure rate was calculated as previously described by Moacă et al. [26]:

\section{Scratch closure $=\left[\frac{A_{t 0}-A_{t}}{A_{t 0}}\right] * 100$ rate}

(2)

where: $A_{t 0}$ is the scratch area at time $0 ; A_{t}$ is the scratch area at $24 \mathrm{~h}$.

DAPI (4',6-diamidino-2- phenylindole) staining

In order to investigate the apoptotic potential of Pg at the selected concentration, MCF7 cells were plated to an initial density of $5 \times 10^{5}$ cells/well onto 6-well plates overnight. On the following day, the medium was removed, and the cells were stimulated with a fresh one containing the testing compound to a final concentration of $10,2550,75,100$ and $150 \mu \mathrm{g} / \mathrm{mL}$, respectively, for $72 \mathrm{~h}$. At the end of stimulation period, the medium was removed from the wells and the cells were washed with ice-cold PBS twice and were fixed with 4\% paraformaldehyde in PBS, permeabilized with $2 \%$ Triton- X/PBS for 30 min, followed by a blocking step with $30 \%$ FCS $/ 0,01 \%$ Triton-X. Finally, the cells were washed with PBS and stained with DAPI (300 nM) in a dark chamber for 15 min. Fluorescent images were taken at a magnification of 40X, with a fluorescence inverted microscope Olympus IX73, equipped with an integrated DP74 digital camera (Olympus, Tokyo, Japan).

\section{Cell cycle analysis}

To characterize cell cycle distribution, the DNA content analysis of the cells was determined by FACSCalibur flow cytometer (Becton-Dickinson, Franklin Lakes, NJ, USA). The MCF7 human breast cancer cells were seeded into 6 well plates and treated with poplar bud extracts. After $48 \mathrm{~h}$ the cells were collected and fixed with cold $70 \%$ ethanol $(1000 \mu \mathrm{l})$ and stored for $30 \mathrm{~min}$ at $4^{\circ} \mathrm{C}$. After centrifugation (1500 RPM, 5 min), cold PBS was used to wash the cells. Afterwards, $50 \mu$ of propidium iodide (BD Pharmingen, BD Biosciences) were added to the cells and then incubated for 10 minutes at $4^{\circ} \mathrm{C}$. The untreated cells and the cells treated with $0.15 \%$ DMSO were used as a control and solvent control respectively. As a final step the percentage of cells present in the different cell cycle (G0, G1, S, G2) phases was determined using Flowing software 2.5.1.

Annexin V-FITC apoptosis assay

The Pg extract was screened for the flow cytometric analysis with Annexin V-FITC apoptosis detection kit (Sigma-Aldrich) following the manufacturer's protocol. A number of $10^{4}$ cells/well were seeded into a 6-well plate and left overnight. After $24 \mathrm{~h}$, the media was removed and were added fresh medium treated with Pg extracts $(10,25,50,75,100,150 \mu \mathrm{g} / \mathrm{mL})$. After $72 \mathrm{~h}$ the cells were trypsinized and were washed two times with Binding Buffer, centrifuged at 1500 RPM for 7 minutes, resuspended in Binding Buffer and incubated with $5 \mu \mathrm{L}$ of Annexin V-FITC for 15 min at room temperature. After cell washing, the cell pellet was resuspended in a $190 \mu \mathrm{L}$ Binding Buffer with $10 \mu \mathrm{L}$ PI solution (propidium iodide). As control was used the untreated cells, and as a solvent control was used cells treated with 0,15\% DMSO. Cells were analyzed by flow cytometry (FACSCalibur, Becton Dickinson) using the fluorescence channel FL1 for annexin and FL2 for PI. The results were analyzed using Flowing Software 2.5.1.

\section{Angiogenesis evaluation using the chick chorioallantoic membrane (CAM) assay}

In order to investigate the effects of the $\mathrm{Pg}$ on the process of angiogenesis we conducted an in vivo experiment using as biological material the chorioallantoic membrane of fertilized chicken (Gallus gallus domesticus) eggs under development. The eggs were incubated at $37^{\circ} \mathrm{C}$ and $50 \%$ humidity and were prepared according to the basic protocol with some modifications $[25,27]$. On the third day of incubation $5-6$ ml of albumen were removed, and subsequently an opening was cut on the upper side of the eggs. The eggs were further incubated until day 7 of incubation, when $10 \mu \mathrm{l}$ of test $(\mathrm{Pg} 150 \mu \mathrm{g} / \mathrm{mL}$ ) and control (0.1\% DMSO v/v in double distilled water) samples were inoculated inside plastic rings on the developing vascular plexus of the CAM. Application of the samples was repeated daily (24h, $48 \mathrm{~h})$ and was followed by stereomicroscopic 
monitoring, capturing relevant in ovo images (Discovery 8 Stereomicroscope, Zeiss, coupled to Axio CAM 105 color, Zeiss digital camera). The photographs were further processed by Zeiss ZEN software, ImageJ and GIMP.

\section{Immunomodulatory activity}

Cell viability and apoptosis assay

Cytotoxic effects of the Pg extract on dendritic cells were analyzed by FACS staining with DAPI for cell viability and Annexin V/7AAD for apoptosis.

Additionally, to the stimulation of the differentiated inflammatory dendritic cells with the Pg extract in different concentrations, $1 \mu \mathrm{M}$ Staurosporin (LC Laboratories, MA, USA) was used as a positive control for apoptosis. After $24 \mathrm{~h}$ cells were harvested and washed twice with Annexin Binding Buffer (0,1 M NaCl, 25mM CaCl2, 0,1M Hepes), resuspended in $500 \mu$ l Annexin Binding Buffer and stained with $5 \mu$ l Annexin V FITC (Immunotools, Friesoythe; Germany) per tube for 15 minutes in the dark. After this incubation $5 \mu$ of 7AAD (Invitrogen, MA, USA) was added and stained for further 5 minutes in the dark. The cells were pelleted and resuspended in 400 $\mu$ l Annexin Binding Puffer containing 100 ng/ml DAPI (Sigma, Merck, Darmstadt) for cell viability staining. During the next hour the samples were measured using FACS Canto II, the data were analyzed with FlowJo software 7.6.5.

Cytokine analysis

The supernatants were analyzed by ELISAs for IL-10 and IL-23 (R\&D Systems, Wiesbaden, Germany) according to the manufacturer's manual. The cell pellet was harvested, and total RNA was extracted using the peqGOLD Total RNA Kit (peqlab, Erlangen, Germany) as recommended by the manufacturer. RNA concentration was measured using the Nano-Drop 1000 analyzer (Thermo Scientific) and adjusted to $1 \mu \mathrm{g} / \mu \mathrm{L}$ for cDNA synthesis using the high-capacity cDNA reverse transcription kit (Life Technologies, Carlsbad, CA). TaqMan® gene expression assays (Thermo Fisher, Dreieich, Germany) were applied for all genes of interest and for the housekeeping genes gapdh and fbxo38, (Primer Design, Southampton, UK). The Precision FAST Mastermix (Primer Design) was used and quantitative real-time PCR was run according to manufactures' recommendations (7500 Fast Real-Time PCR System, Applied Biosystems). Data were evaluated using the mean of the two housekeeping genes as a reference.

\section{Statistical analysis}

The results obtained in the in vitro assay are expressed as mean \pm standard deviation. Comparison among groups was made using One-way ANOVA test and Dunnett's multiple comparison post-test. For the statistical analysis GraphPad Prism 5 (GraphPad Software, San Diego, CA, USA) was used.

\section{Results}

\section{Antioxidant activity}

The antioxidant activity of the hydroalcoholic extract obtained from Pg was determined spectrophotometrically, by radical scavenging 2,2diphenyl-1-picrylhydrazyl (DPPH) assay using Ascorbic acid as a standard reference. Table 1 shows the percentage of inhibition obtained after evaluating the $\mathrm{Pg}$ hydroalcoholic extracts as a function of their concentration. It can be seen that the five concentrations of tested Pg extracts have very high antioxidant activity, almost comparable to the AOA of the standard reference (vitamin $\mathrm{C}$ ethanolic solution). Both the antioxidant activity of $\mathrm{Pg}$ extracts and the $\mathrm{AOA}$ of different concentrations of vitamin $\mathrm{C}$, expressed as a percentage, were calculated with equation (1), presented above. The analyzes were performed three times, for each hydroalcoholic extract, respectively each concentration of vitamin $\mathrm{C}$ separately, thus calculating the standard deviation. The mean of the AOA obtained for each analyzed sample was used to determine the IC $C_{50}$ values, IC ${ }_{10}, I_{20}, I C_{80}$ and $\mathrm{IC}_{90}$, respectively, presented in Table 2. The percentage of inhibition in the case of the analyzed ethanolic Pg extract varies from $95-97.3 \%$, while in the case of vitamin $\mathrm{C}$, between $97.5 \%-98.9 \%$. As already well known $\mathrm{IC}_{50}$ is the average inhibitory concentration (represents the maximum concentration of the hydroalcoholic extract of Pg, necessary to inhibit $50 \%$ of the standard oxidant used DPPH), an operational value, depending on the test conditions. All determined inhibitory concentrations, expressed in Table $2, I_{50}$ as well as $I_{90}$ - the inhibitory concentration required to inhibit $90 \%$ of the standard oxidant, were determined to establish complete inhibition. Assuming the binding of DPPH to the antioxidants contained in the $\mathrm{Pg}$ extract, in a single place at equilibrium, with a Hill coefficient equal to $1, I_{90}$ should have been 10 times higher than IC ${ }_{50}[30]$. But for a competitive inhibitor (such as $\mathrm{Pg}$ ethanolic extract), $\mathrm{IC}_{50}$ increases with increasing concentration. Figure 1 shows the reaction kinetics, analyzed for 1200 seconds for each concentration of Pg ethanolic extract mixed with DPPH, compared to the reaction kinetics between vitamin $\mathrm{C}$ and DPPH. From the graph it can be seen that Pg extract analyzed at the lowest concentration $(\mathrm{Pg} 50 \mu \mathrm{g} / \mathrm{mL})$ reacts slowly with the DPPH radical, the reaction reaching equilibrium only after 1100 seconds. As the lowest concentration tested over time reacts with the standard oxidant, it confirms that the Pg ethanolic extract is a competitive inhibitor of vitamin C, which is a non-competitive inhibitor, consuming the entire amount of DPPH in the first 20 seconds from the start of the reaction. The fact that vitamin $\mathrm{C}$ is a non-competitive inhibitor also results from the fact that the same value of the inhibition percentage was obtained both at the concentration of $25 \mu \mathrm{g} / \mathrm{mL}$ as well as at the concentration of $200 \mu \mathrm{g} / \mathrm{mL}$ concentration. The rest of the screened Pg concentrations reached faster the equilibrium (interval between 100-400 seconds, depending on the concentration), consuming the

Page $7 / 27$ 
entire amount of DPPH after this interval. The fact that Pg extract is a competitive inhibitor also results from the small fluctuations observed in Figure 1, recorded until the redox reaction reached equilibrium.

Table 1

The percent of $\mathrm{AOA}$ induced by vitamin $\mathrm{C}$ as compared to $\mathrm{Pg}$ extracts.

\begin{tabular}{|llll|}
\hline Vitamin C & \multicolumn{3}{|c|}{$P g$ extracts } \\
\hline Conc. $[\mu \mathrm{g} / \mathrm{mL}]$ & $\%$ inhibition & Conc. $[\mu \mathrm{g} / \mathrm{mL}]$ & $\%$ inhibition \\
\hline 25 & $98.90561 \pm 0.0009$ & 50 & $95.07524 \pm 0.0039$ \\
\hline 50 & $97.53762 \pm 0.0019$ & 100 & $97.26402 \pm 0.0022$ \\
\hline 100 & $98.49521 \pm 0.0012$ & 250 & $96.16963 \pm 0.0030$ \\
\hline 200 & $98.90561 \pm 0.0009$ & 500 & $96.99042 \pm 0.0024$ \\
\hline 300 & $97.81112 \pm 0.0017$ & 1000 & $96.99042 \pm 0.0024$ \\
\hline 400 & $98.76881 \pm 0.0010$ & & \\
\hline
\end{tabular}

Table 2

The concentrations of the inhibitors (vitamin $\mathrm{C}$ and $\mathrm{Pg}$ extracts) where the response is reduced by half

$\left(\mathrm{IC}_{50}\right)$, at $10 \%$ response $\left(\mathrm{IC}_{10}\right)$, at $20 \%$ response $\left(\mathrm{IC}_{20}\right)$, at $80 \%$ response $\left(\mathrm{IC}_{80}\right)$ and at $90 \%$ response

$\left(\mathrm{IC}_{90}\right)$.

\begin{tabular}{|llllll|}
\hline & $I_{50}[\mu \mathrm{g} / \mathrm{mL}]$ & $I C_{10}[\mu \mathrm{g} / \mathrm{mL}]$ & $I^{2}[\mu \mathrm{g} / \mathrm{mL}]$ & $I_{80}[\mu \mathrm{g} / \mathrm{mL}]$ & $I_{90}[\mu \mathrm{g} / \mathrm{mL}]$ \\
\hline Vitamin C & $2.26599 \pm 3.16$ & $2.39958 \pm 5.10$ & $2.34938 \pm 4.36$ & $2.18555 \pm 2.05$ & $2.13938 \pm 1.43$ \\
\hline Pg extract & $0.36431 \pm 0.52$ & $0.10804 \pm 0.26$ & $0.16921 \pm 0.34$ & $0.78436 \pm 0.66$ & $1.2284 \pm$ \\
& & & & & 0.61 \\
\hline
\end{tabular}

\section{Physicochemical screening}

Fourier-transform infrared spectroscopy (FT-IR) spectroscopy

In Figure 2 and Table 3 are given the results of FT-IR analysis of Pg dried extract. The interpretation of the FT-IR spectra was performed in accordance with the Characteristic IR Absorption Frequencies of Organic Functional Groups [31]. As can be seen, FT-IR spectra had some relevant absorption peak at, $2926.01 \mathrm{~cm}^{-1}, 1629.85$ and $1604.77 \mathrm{~cm}^{-1}, 1267.23 \mathrm{~cm}^{-1}$ and $1074.35 \mathrm{~cm}^{-1}$. The peak identified at $3392.79 \mathrm{~cm}-1$, points out a broad band usually assigned to the stretching vibration of $\mathrm{O}-\mathrm{H}$ from hydroxyl groups $(\mathrm{H}$ - bonded) and water. Hydroxyl groups may belong to the

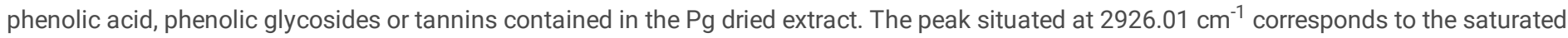
aliphatic $\mathrm{C}-\mathrm{H}$ bands. Saturated aliphatic $\mathrm{C}-\mathrm{H}$ bands are due to the presence of tannins in the analyzed extract [32]. The peaks at 1629.85 and $1604.77 \mathrm{~cm}^{-1}$ may be assigned to stretching vibration of $\mathrm{C}=\mathrm{C}$ bands. This $\mathrm{C}=\mathrm{C}$ band confirms either the presence of alkene functional group, or the presence of aromatic functional group. Most probable, this band is assigned to the aromatic functional group, due to the medium-weak intensity of the absorption peak and to the multiple bands recorded.

The band located at $1267.23 \mathrm{~cm}^{-1}$ is assigned to stretching the vibration of $\mathrm{C}-\mathrm{O}$ bands. This $\mathrm{C}-\mathrm{O}$ band confirms the presence of a carbonyl acid as well as the presence of ethers in the analyzed extract. Could also be the presence of an ester, but we rule out the possibility due to the fact that regarding the intensity, esters should present two bands or more recorded on the spectra. Whereas, the band located at $1267.23 \mathrm{~cm}^{-1}$ is not so broad, rather is medium-weak intensity with a stretch vibration type. We believe that in the analyzed extract, amine groups are also present like $\mathrm{C}-\mathrm{N}$ bands (phenolic acids from Pg dried extract), also confirmed by the presence of the band from $1163.08 \mathrm{~cm}^{-1}$ with a medium intensity. The band located at $1074.35 \mathrm{~cm}^{-1}$ is assigned to a stretching vibration of $\mathrm{C}-\mathrm{O}$ bands, present in alcohol functional groups (monoterpenes and non-terpenes contained in the extract) and/or to a stretching vibration of $\mathrm{C}-\mathrm{O}$ bands, present in ester functional group, due to the appearance of the second bands on FT-IR spectra $\left(1033.85 \mathrm{~cm}^{-1}\right)$. The flavonoids/flavonols present in the Pg dried extract contain ester-like functional groups in their structure. The last three bands highlighted on the FT-IR spectra $\left(765.74 ; 698.23\right.$ and $\left.518.85 \mathrm{~cm}^{-1}\right)$ may be due to both the present of alkene functional groups (765.74 and $698.23 \mathrm{~cm}^{-1}$ - assigned to a bending vibration of $=\mathrm{C}-\mathrm{H}$ bands, belonging to the aldehides from $\mathrm{Pg}$ dried extract) as well as alkyl halide functional groups, assigned to a stretching vibration of $\mathrm{C}$ - $\mathrm{Cl}$ bands. As in the case of the two bands described above, the band located at $518.85 \mathrm{~cm}^{-1}$ (assigned to $\mathrm{C}-\mathrm{Br}$ bands from the alkyl halide functional groups) the presence of these compounds may be due either the presence of some minerals that have been absorbed by buds from the soil through the poplar (concentrating over time), or due to the impurity of the extract at preparation time or even at characterization time. All the absorption peaks recorded following the FT-IR analysis as well as functional groups together with characteristic absorption band and intensity, are given in Table 3.

Thermal analysis

Page $8 / 27$ 
The Thermogravimetry- Differential Scanning Calorimetry (TG-DSC) graphic of dried Pg extract is presented in Figure 3.

As can be seen the thermal analysis conducted to the fact that the total mass loss of $96.84 \%$ in four stages. In the first stage, the lowest mass loss occurs $(8.72 \%)$ of the total mass without energy changes, noticeable on the DSC curve. The same thing happens both in the second stage, located between $150-300^{\circ} \mathrm{C}$, as well as in the third stage $\left(300-400^{\circ} \mathrm{C}\right)$; the only recorded effects on the TG curve are weight changes $(25.65 \%$ - on the second stage and 18.06 on the third stage). In the fourth stage of Pg extract degradation, located between 400 and $800^{\circ} \mathrm{C}$ it takes place the largest mass loss (44.2\%), accompanied by an exothermic process with a maximum at $547.3^{\circ} \mathrm{C}$. After that, the complete degradation of the extract occurs, because no mass changes on TG curve were recorded. The exothermic effect noticed on the DSC curve, could be related with the degradation of aromatic

compounds, carbohydrates and aromatic amino acids present in the dried extract of Pg.

In vitro antimicrobial effects

The Gram-negative bacilli strains, especially Escherichia coli and Pseudomonas aeruginosa presented significant inhibitory activity at the tested concentrations. The inhibition diameters are presented in Table 4. Table 5 presents the results on the minimum inhibitory concentration (MIC) and Minimum bactericidal concentration (MBC) values. The MIC values for Streptococcus pyogenes and Streptococcus mutans

Table 3

Peak values and functional groups of Pg dried extract in the FT-IR spectra

\begin{tabular}{|c|c|c|c|}
\hline $\begin{array}{l}\text { Characteristic absorptions }\left[\mathrm{cm}^{-1}\right] \\
\text { leaves extract / stems extract }\end{array}$ & Functional group & Bond & Intensity \\
\hline 3392.79 & Alcohol & $\begin{array}{l}\text { O-H stretch } \\
\text { (H-bonded) }\end{array}$ & Strong, broad \\
\hline 2926.01 & Alkanes & C-H stretch & Strong \\
\hline 2854.65 & Aldehyde & $=\mathrm{C}-\mathrm{H}$ stretch & Medium, two peaks \\
\hline $1685.79 / 1629.85$ & Alkene & $\mathrm{C}=\mathrm{C}$ stretch & Variable \\
\hline 1604.77 & Aromatics & $\mathrm{C}=\mathrm{C}$ stretch & Medium-weak, multiple bands \\
\hline $1514.12 / 1375.25$ & Nitro & $\mathrm{N}-\mathrm{O}$ stretch & Strong, two bands \\
\hline 1450.47 & Alkane & $\mathrm{C}-\mathrm{H}$ bending & Variable \\
\hline \multirow[t]{2}{*}{1267.23} & Carbonyl acids & C-O stretch & Strong \\
\hline & Amine & C-N stretch & Medium - weak \\
\hline 1163.08 & Amine & C-N stretch & Medium - weak \\
\hline \multirow[t]{2}{*}{$1074.35 / 1033.85$} & Alcohol & C-O strecth & Strong \\
\hline & Ester & C-O stretch & Two bands or more \\
\hline \multirow[t]{2}{*}{831.32 / 765.74 / 698.23} & Alkene & $=\mathrm{C}-\mathrm{H}$ bending & Strong \\
\hline & Alkyl Halide & C-Cl stretch & Strong \\
\hline 518.85 & Alkyl Halide & C-Br stretch & Strong \\
\hline
\end{tabular}

Table 4

The inhibition diameters for selected strains after incubation with $\mathrm{Pg}$.

\begin{tabular}{|c|c|c|c|c|c|c|c|c|}
\hline Compound & $\begin{array}{l}\text { Streptococcus } \\
\text { pyogenes }\end{array}$ & $\begin{array}{l}\text { Streptococcus } \\
\text { mutans }\end{array}$ & $\begin{array}{l}\text { Staphylococcus } \\
\text { aureus }\end{array}$ & $\begin{array}{l}\text { Enterococcus } \\
\text { faecalis }\end{array}$ & $\begin{array}{l}\text { Escherichia } \\
\text { coli }\end{array}$ & $\begin{array}{l}\text { Pseudomonas } \\
\text { aeruginosa }\end{array}$ & $\begin{array}{l}\text { Candida } \\
\text { albicans }\end{array}$ & $\begin{array}{l}\text { Candida } \\
\text { parapsilosis }\end{array}$ \\
\hline$P G$ & $23 \mathrm{~mm}$ & $26 \mathrm{~mm}$ & $15 \mathrm{~mm}$ & $13 \mathrm{~mm}$ & $7 \mathrm{~mm}$ & $8 \mathrm{~mm}$ & $17 \mathrm{~mm}$ & $17 \mathrm{~mm}$ \\
\hline
\end{tabular}


Table 5

The minimum inhibitory concentration (MIC) and the minimum bactericidal concentration (MBC).

\begin{tabular}{|lll|}
\hline Species & MIC $(\mathrm{mg} / \mathrm{mL})$ & $\mathrm{MBC}(\mathrm{mg} / \mathrm{mL})$ \\
\hline S. pyogenes & 0.312 & 0.312 \\
S. mutans & 0.312 & 0.312 \\
\hline S. aureus & 0.625 & 2.5 \\
\hline E. faecalis & 2.5 & - \\
\hline E. coli & - & - \\
\hline P. aeruginosa & - & - \\
\hline C. albicans & 1.25 & 2.5 \\
\hline C. parapsilosis & 1.25 & 2.5 \\
\hline
\end{tabular}

$(0.312 \mathrm{mg} / \mathrm{mL})$ were lower than those for Staphylococcus aureus $(0.625 \mathrm{mg} / \mathrm{mL})$ and Eenterococcus faecalis $(2.5 \mathrm{mg} / \mathrm{mL})$. The $\mathrm{MBC}$ values were very appropriate to the MIC values. Based on these results, we can affirm that screened Pg extracts present bactericidal effects only against the Gram-positive cocci and Candida spp. The extract does not have any activity on Pseudomonas aeruginosa and Escherichia coli strains.

\section{Anticancer activity}

MTT(3-(4,5-dimethylthiazol-2-yl)-2,5 diphenyl tetra zoli-um bromide) assay

The effect of Pg extract was assessed on MCF7 human breast adenocarcinoma cell lines and compared to the Control group, which are cells that were stimulated with the solvent dimethyl sulfoxide (DMSO). Also, a non-tumorigenic cell line was used (MCF-10A breast epithelial cells) in order to demonstrate the selectivity of the screened samples on cancer cells. In Figure 4 is represented the effect of Pg extract on MCF7 human breast adenocarcinoma cells after a stimulation period of $72 \mathrm{~h}$. The $\mathrm{IC}_{50}$ value of Pg extracts on MCF7 human breast adenocarcinoma cells after $72 \mathrm{~h}$ post-stimulation was $66.26 \mu \mathrm{g} / \mathrm{mL}$. Treatment with Pg extract elicited a dose-dependent decrease of tumor cell viability. At the highest tested dose used, tumor cells viability was decreased to $37.5 \pm 2 \%$ vs. Control. Figure 5 depicts the effect of Pg extract on MCF- $10 \mathrm{~A}$ breast epithelial cells after $72 \mathrm{~h}$ stimulation. It can be observed that at the lowest dose tested $(10 \mu \mathrm{g} / \mathrm{mL})$, the extract produced a significant increase in cells viability $(119.03 \pm$ $9 \%$ vs. Control). Only at the highest doses tested a decrease in cells viability was noticed (for $100 \mu \mathrm{g} / \mathrm{mL}$ cells viability was $84.4 \pm 4.9 \%$ vs. Control and for $150 \mu \mathrm{g} / \mathrm{mL}$ cells viability was $79.8 \pm 3 \%$ vs. Control). The results obtained indicate that Pg extract is selective on the screened cancer cell line, affecting in a low manner the non-tumor cell line affects more the breast tumor cells than the healthy cell line.

Determination of the Cytotoxic Potential by Lactate Dehydrogenase (LDH) Release

In order to evaluate the cytotoxic potential of Pg extract at the selected concentrations, lactate dehydrogenase assay was performed. After the $72 \mathrm{~h}$ stimulation period of MCF7 cells a dose dependent increase in the release of lactate dehydrogenase was observed (Figure 6), indicating that the extract produced a cytotoxic effect on the cancer cell line. At the highest dose tested dose $(150 \mu \mathrm{g} / \mathrm{mL})$ the cytotoxic rate was $37 \pm 4.1 \%$ vs. Control $(5 \pm 1.1 \%)$.

Scratch assay

On MCF7 human breast adenocarcinoma cells the Pg extract inhibited cell migration and proliferation in dosedependent manner (Figure 7 (a), (b)). Furthermore,

at the highest tested doses $(100$ and $150 \mathrm{ug} / \mathrm{mL}) \mathrm{Pg}$ extract also generates changes in tumor cell morphology and some of the cells start to be detached.

In Figure 7 (c) is depicted the Scratch closure rate for all the concentrations. It can be observed that Pg extract produced a dose-dependent decrease in the closure rate showing that the sample elicited an anti-migratory effect on MCF7 breast adenocarcinoma cells. At the highest doses tested doses the scratch closure rate was $1.4 \%$ for $100 \mu \mathrm{g} / \mathrm{mL}$ and $1.3 \%$ for $150 \mu \mathrm{g} / \mathrm{mL}$.

DAPI (4',6-diamidino-2- phenylindole) staining

Figure 8 depicts the DAPI staining of MCF7 breast adenocarcinoma cells: the images show that chromatin condensation is increasing dosedependent and that there are signs of nuclear membrane blebbing. These results indicate that there are signs of apoptosis in MCF7 cells following treatment with Pg extract. Deoxyribonucleic acid (DNA) fragmentation was not observed under the current experimental conditions. In the Control cells the chromatin density was equally dispersed. 
To better understand the mechanism of inhibition of cell proliferation, the distribution of cells in the different phases of the cell cycle was analyzed following treatment with 10, 25, 50, 75, 100, $150 \mu \mathrm{g} / \mathrm{mL}$ Pg for 72 hours. A slight increase of the cells in G0/G1 phase with a concomitant decrease in cells in the G2/M phase was observed, but the G0/G1 arrest was not in a dose-dependent manner, the percentage of cells in G0/G1 phase increasing from $56.97 \pm 8.93 \%$ (control) up to $62.46 \pm 11.93(10 \mu \mathrm{g} / \mathrm{mL})$ or $61.96 \pm 4.05 \%(150 \mu \mathrm{g} / \mathrm{mL})$. Figure 9 presents the results of all cell cycle experiments.

Annexin V-Propidium iodide (PI)

Annexin-PI double staining assay is a commonly used approach for achieving information regarding phenomena of early apoptosis, late apoptosis and necrosis. The representative flow-cytometry dot-plots for the cells treated with different concentrations of Pg (10, 25, 50, 75, 100,150 mg), control and DMSO are presented in Figure 10. Lower right quadrant represents early apoptotic cells while upper right quadrant and upper left quadrant represent late apoptotic cells and necrotic cells respectively. One can notice that $\mathrm{Pg}$ at the maximum concentration tested (150 $\mu \mathrm{g} / \mathrm{mL}$ ) caused early apoptotic events in a dose-dependent manner when compared to control $(0.07 \% \pm 0.05 \%$ vs. $45.53 \% \pm 6.5 \%)$. One can notice that Pg had an apoptotic effect on MCF7 cells in a dose-dependent manner, inducing early apoptosis and late apoptosis. The percentage in early apoptotic cells after $72 \mathrm{~h}$ of treatment with Pg extract, increased dramatically from $0.07 \% \pm 0.05$ in case of untreated cells, up to $45.53 \% \pm 6.50$ in case of $150 \mu \mathrm{g} / \mathrm{mL}$. As shown in Figures 10 and 11 lower concentrations had a proapoptotic effect, with the percentage of early apoptotic cell as follow: the lowest concentration $(10 \mu \mathrm{g} / \mathrm{mL}$ ) lead to an increase of $2.63 \% \pm 3.72$, while $25,50,75$ and $100 \mu \mathrm{g} / \mathrm{mL}$ lead to an increase of $3.73 \% \pm 4.49$, $8.85 \% \pm 9.55,13.33 \% \pm 11.12,28.83 \% \pm 4.68$, respectively $(p<0.001)$. Regarding the late apoptosis, a slight increase in late apoptotic cells was observed starting with the concentration of $50 \mu \mathrm{g} / \mathrm{mL}(0.44 \% \pm 0.32$ compared with $0.04 \% \pm 0.03$ for control) increasing progressively up to $1.74 \%$ \pm 0.25 and $3.11 \% \pm 3.08$ for 100 and $150 \mu \mathrm{g} / \mathrm{mL}$, respectively $(\mathrm{p}<0.01)$.

\section{Chorioallantoic Membrane (Cam) Assay}

We investigated the potential implication of a Pg extract in the process of neovascularization using a largely applied in vivo method that involves an intensively irrigated extraembryonic membrane. The protocol allows the investigation of modification induced by the test samples on the normal process of angiogenesis, and moreover, by choosing as application interval between the embryonic days of development (EDD) 7-11, the compounds are evaluated on a rapidly developing capillary bed [33]. Therefore, the evaluation is highly useful as prescreening for tumor angiogenic assays. The experimental setting also allows to detect potential bioavailability and toxicity of the administered solutions upon mucosal tissues. Pg extract in the concentration of $150 \mu \mathrm{g} / \mathrm{mL}$ was well tolerated, no signs of toxicity upon vascular plexus were signaled in terms of coagulability. Still, some modifications upon vessel development were observed. Already after only one dose and 24 hours of contact with Pg samples, areas inside the application ring on CAM showed a reduced degree of capillary interconnection (Figure 12). Inside the application spot there are areas with a very low number of newly formed vessels, when compared to non-treated areas. Also, when evaluating the control sample, a higher degree of developing vascularization is observed inside the ring, 24 and 48 hours after application.

\section{Immunomodulatory effects}

Cell viability

To investigate the immunomodulatory effects of the Pg extract, human primary peripheral blood mononuclear cells (PBMCs) were isolated from blood, differentiated into dendritic cells (DCs), and stimulated with the Pg extract. In this set of experiments, we included also lower concentrations of the Pg extract (1-10 $\mu \mathrm{g} / \mathrm{mL})$, since immune cell activity and cytokine release can be very sensitive to slight stimulation. The cell viability of the dendritic cells was assessed with FACS after $24 \mathrm{~h}$ of stimulation with the Pg extract in different concentrations or a DMSO control, in the absence (naïve) or presence of an inflammatory stimulation with LPS (inflammatory). DAPI staining revealed no cytotoxic effect of low and moderate Pg extract concentrations on naïve and inflammatory DCs (Figure 13). Very high concentrations (75 and $100 \mu \mathrm{g} / \mathrm{mL}$ ) seemed to induce cell toxicity in some experiments, not reaching statistical differences.

To go in more detail, cells were assessed further for late apoptosis (Figure 14). From the data it is clear, that only cells stimulated with very low concentrations of the extract (1-10 ug) did not enter the apoptotic pathway. Especially in inflammatory DCs, concentrations above 25 ug/ml lead to the induction of apoptotic processes in the cells.

Representative transmitted light microscopic images of Pg extract-stimulated human dendritic cells are presented in Figure 15 and strengthen the impression that high Pg extract amounts are harmful to cell morphology. With increasing Pg extract concentrations, inflammatory cells start to round up and lose their spindle-like shape.

Cytokine expression and release 
Cytokine secretion was analyzed in order to see if the Pg extract stimulation had functional consequences on DCs. The Pg extract was not able to activate naïve DCs (Figure 16).

A significant increase in IL-10 and IL-23 secretion was achieved with low Pg extract concentrations on inflammatory DCs (Figure 17). Very high Pg extract concentrations (75 and $100 \mu \mathrm{g} / \mathrm{mL}$ ) however decreased cytokine production in inflammatory DCs.

On messenger Ribonucleic acid (mRNA) level we analyzed the expression of the IL-12 and IL-23 subunits p19, p35 and p40 and found that both, p19 and p35 mRNA levels were significantly upregulated with an extract concentration of $10 \mu \mathrm{g} / \mathrm{ml}$ in naïve DCs (Figure 18). On already activated DCs, the Pg extract had no effect on mRNA expression of the subunits.

\section{Discussion}

In the same research topic, the phytochemical composition of the ethanolic extract of Romanian poplar buds was detailed in a previous paper recently published by our research group. Briefly the extract was found to contain mainly the following phenolic compounds: dihydroxybenzoic acid, protocatechuic acid, 3-caffeoylquinic acid, 5-caffeoylquinic acid, caffeic acid, chicoric acid, apigenin-glucuronide, chrysoeriolglucuronide, tremuloidin, salicin, pinostrobin, and tremulacin [34]. In a similar approach, Greenway et al. tested the chemical composition of Populus nigra L. bud exudates from 7 countries (Netherlands, Russia, Belgium, United Kingdom, France, Italy and China) and reported that all screened samples contain high levels of caffeic and isoferulic acids on one hand but low levels of cinnamic and coumaric acids on the other hand. Only one sample (United Kingdom) showed an increased percentage of pinocembrin, pinobanksin, chrysin and also galangin [35]. In a comprehensive study, Jerković et al. described the phytochemical composition of volatile components from fresh and air-dried leaf-buds of Populus nigra L. (Croatia). They reported the presence of more than 48 phytocompounds, among which sesquiterpenes ( $\beta$-eudesmol and $a$-eudesmol, $\gamma$-cadinene, $a$-elemene) and in a low percentage monoterpene, aliphatic and aromatic alcohols, carbonyl compounds have been detected [7]. The water, chloroform, methanol and hexane extract of black poplar buds (Algeria) indicate a rich source of flavonoids, polyphenols, terpenoids, polyphenols and also tannins. On the contrary, beside these compounds the author reported an absence of saponosides and anthocyanins [36]. In a recent study Ristivojević et al. reported that the ethanolic extract of poplar bud (Serbia) contains phenolic acids and their derivates (caffeic acid, p-coumaric acid), flavonols, flavanonols, flavan-3-ols, glycosides (apigenin-7-0-glucoside) and phenolic glycerides [6]. Other studies mentioned higher flavonoids (pinocembrin, pinobanksin) and phenolic acids (caffeic, cinnamic, coumaric, ferulic acid) content for the aqueous black poplar bud extract (Bulgaria) [37]. In a similar study conducted by Rubiolo et al., the black poplar bud absolute (France) exhibited a high presence of flavonoids and phenolic acids including chrysin, galangin, pinocembrin, pinostrobin and also tectochrysin [29].

As revealed in the results section the screened Pg extract shows a significant antioxidant potential. The DPPH assay is the most widely used method of determining the antioxidant activity (AOA) of natural extracts, which is based on the decolorization of the DPPH solution from deep purple to pale yellow in the presence of a hydrogen donor, establishing the degree of inhibition of free radicals [17]. Results from this study are in agreement with those obtained by Mainar et al. Using the same assay (DPPH) this research group evaluates the antioxidant activity of the ethanolic extract of black poplar bud (Spain) concluding that this extract is a natural source of antioxidants [38]. Merghache et al. also pointed out the antioxidant activity of the hydroalcoholic extract of black poplar bud (Algeria). They revealed that the highest antioxidant potential was achieved at $1000 \mu \mathrm{g} / \mathrm{mL}$, comparable with the ascorbic acid activity [36]. Staying in the same directions, Debbache et al. have exploited the antioxidant potential of seven extracts (ethanol, hexane, aqueous of ethyl acetate, ethyl acetate, aqueous of hexane, chloroform and aqueous of chloroform) of black poplar buds (Algeria). As revealed by their study the aqueous fraction of chloroform extract present the highest activity and it can be used as an accessible source of natural antioxidant [39].

To the best of our knowledge, this is the first study focusing on the evaluation of Pg extract, including the thermal behavior and the FT-IR spectroscopy analysis. The results of the present study are in agreement with literature data, although most research studies are focused on the quantitative identification of active compounds from different poplar bud preparations (extraction, infusion, essential oil). The FT-IR analysis performed in the present study demonstrated the identification of the same active compounds, such as: flavonoids/flavonols (pinocembrin and pinostrobin); phenolic acids; phenolic glycosides (salicilin, populin); tannins [7, 14, 40, 41, 42, 43, 44]. Indeed, the FT-IR analysis is not sufficient. In order to establish to which active compound the biologically effects are due, the identification and quantification with high precision it's necessary, this being possible only through the high-performance liquid chromatography (HPLC) technique. According to the FT-IR analysis, the active compounds contained in the dried extract were phenolic acids; phenolic glycosides (salicilin, populin); flavonoids/flavonols (pinocembrin and pinostrobin); tannins. The active compounds present in Pg dried extract have different degradation temperatures. For instance, Cheng and collaborators have investigated the decomposition of five phenolic compounds in high temperature water [45]. The authors found that three phenolic acids were decomposed at $250^{\circ} \mathrm{C}$ and the other two were completely degraded until $350^{\circ} \mathrm{C}$. In the study conducted by Chaaban and coworkers [46], the authors have investigated the effect of heat processing on thermal stability and antioxidant activity of six flavonoids. The complete degradation of the investigated flavonoids was in the range of $50-130^{\circ} \mathrm{C}$.

As indicated by other research group, the decomposition profile of the tannins starts at approx. $200^{\circ} \mathrm{C}$ in one stage [32]. In the first stage, the maximum weight loss of the tannins degradation occurs but, in the case of condensed tannins, with a complex aromatic structure, the thermal degradation is almost complete at $600^{\circ} \mathrm{C}$ [32]. Considering the exothermic process recorded on the DSC curve $\left(547.3^{\circ} \mathrm{C}\right)$, we can affirm that this 
thermal effect is associated with the degradation of aromatic compounds contained in condensed tannins from Pg dried extract, occurring in one stage. In the present study, the fact that up to $400^{\circ} \mathrm{C}$ no thermal effect was recorded on the DSC curve, is due to the low content of phenolic acids and flavonoids contained in the Pg dried extract. Their presence in the extract is confirmed by the loss of mass, which is really low, in the first three stages of the analysis.

Black poplar buds possess a wide range of biological activities, among which the most important are their antioxidant, antimicrobial, antiproliferative and anti-inflammatory properties [47].

In the last years, several studies have reported that poplar bud extracts present significant antimicrobial and antifungal activity. As previously mentioned, using the disk diffusion method, data presented in this study showed a remarkable antimicrobial activity against Gram-positive pathogens with important inhibition diameter for Streptococcus pyogenes (23 mm), Streptococcus mutans (26mm) and also Candida species (17 $\mathrm{mm}$ ). Among the screened strains Pg extract was active only on the Gram-positive strains, the best antibacterial effects being detected against Streptococcus pyogene, Streptococcus mutans (both with an MIC and MBC of $0.312 \mathrm{mg} / \mathrm{mL}$ ), followed by Staphylococcus aureus (MIC= 0.625 $\mathrm{mg} / \mathrm{mL}$ ) and Candida strains (MIC $=1.25 \mathrm{mg} / \mathrm{mL}$ ). The study published by Vardar-Unlu et al. reported a similar antimicrobial activity. They tested the Pg methanolic extract against selected Gram-positive bacteria, the most sensitive being Streptococcus pyogenes (MIC of 0.50 mg/ml ${ }^{-1}$ ), Staphylococcus aureus (MIC of $0.50 \mathrm{mg} / \mathrm{ml}^{-1}$ ), Enterococcus faecalis (MIC of $1.00 \mathrm{mg} / \mathrm{ml}^{-1}$ ) [13]. Additionally, Boumghar et al. have concluded that $100 \mu \mathrm{L}$ of poplar bud methanolic and ethanolic extract (Algeria) elicits antimicrobial (using the disk diffusion method) and antibiofilm activity (carried out in a 96-well plate) for Staphylococcus aureus and Bacillus subtilis strains. They demonstrated that the extracts have antibacterial properties against $S$. aureus, Bacillus subtilis and Escherichia coli with diameters ranging from 6.6 to $21.3 \mathrm{~mm}$ [48]. Debbache et al. concluded a study regarding the antimicrobial activity of black poplar buds (Algeria). Their results indicate that the organic extracts exhibited effective antibacterial activity against Escherichia coli, Staphylococcus aureus, Pseudomonas. aeruginosa, Bacillus subtilis and Klebsiella pneumoniae with inhibition zones ranging between 10 and $17 \mathrm{~mm}$ in comparison with Chloramphenicol and Gentamicin. On the other hand, the extracts show moderate activity against the fungal strains, A. niger and F. polyferatum with inhibition zones between 6 and $9 \mathrm{~mm}$ [39]. De Marco et al., reported that the ethanolic extract obtained from poplar bud present an antibacterial potential against Pseudomonas aeruginosa (MIC of $125 \mu \mathrm{g} / \mathrm{mL}$ ) and also shows a strong inhibition of biofilm formation [49]. The present study based on Romanian poplar bud ethanolic extract demonstrate the in vitro antibacterial activity against Gram-positive bacteria, such as Staphylococcus aureus (inhibition zone diameter is $13 \mathrm{~mm}$ ), and also Listeria monocytogenes (inhibition zone diameter is $15 \mathrm{~mm}$ ) [50].

One of the main objectives of this study was to evaluate the potential use of Pg extract as a possible antiproliferative and proapoptotic agent against MCF7 human breast cancer cell line. To the best of our knowledge this approach was never conducted before. In the present work we demonstrate that tested extracts elicit a dose-dependent decrease of tumor cell viability with an IC ${ }_{50}$ of $66.26 \mathrm{ug} / \mathrm{mL}$. Moreover, data have shown that the screened extracts are selective on tumor cells. Although there is a lack of data forwarded towards the black poplar buds antitumoral activity on different cell lines, an increased number of studies have described that Populus nigra L. buds are rich in phytocompounds with anticancer potential. One of these compounds is pinostrobin which was evaluated by Sukardiman et al. In this study the research group assessed the antiproliferative potential against T47D human breast cancer cell line for 10,50, $100 \mathrm{ug} / \mathrm{mL}$ of pinostrobin with check points at $24 \mathrm{~h}$, $48 \mathrm{~h}$ and $72 \mathrm{~h}$. The results indicated that this compound has antitumor activity, moreover it increases the percentage of apoptotic cells [51]. Jaudan et al., investigated the in vitro apoptotic potential of pinostrombin on HeLa cervical cancer cell line and demonstrated a dose dependent growth inhibition potential [52]. Zheng et al., demonstrate that the pinocembrin reduces tumor volume and weight in B16F10 human melanoma cells in vivo on an experimental animal model C57BL/6 mice strain [53].

Apigenin is a natural flavone which is also a part of black poplar bud chemical composition. Cao X et al. demonstrated that apigenin (10, 20, 40, and $80 \mu \mathrm{M}$ ) induce apoptosis on T47D and MDA-MB-231 breast cancer cells in a dose and time dependent manner. Also, they reported an increased level of Bax, decreased level of Bcl-2 and cleaved Caspase 3 and poly ADP-ribose polymerase (PARP) molecules [54]. As discussed in the results section, we have demonstrated that on MCF7 human breast adenocarcinoma cells the Pg extract at the highest doses (100 and 150 $\mu \mathrm{g} / \mathrm{mL}$ ) inhibits the cell migration and proliferation, furthermore it also generates changes in tumor cell morphology. Similar conclusion was drawn by Gao et al. for pinocembrin. The phytocompound (100-200 $\mu \mathrm{M})$ inhibits in vitro the proliferation, migration, and promotes apoptosis on SKOV3 human ovarian cancer cells by down regulating the mRNA levels of $\mathrm{N}$-cadherin and also the gamma-aminobutyric acid (GABAB) receptor [55].

The study published by Buahorm et al. describes the in vitro anticancer potential of cardanol, one of the components of propolis derived from bees foraging on black poplar (Populus nigra L.). Using MTT assay, flow cytometric analysis of Propidium iodide and Annexin-V stained assay, they concluded that this compound induces a time and dose dependent cytotoxicity on BT474 human breast cancer cell line. They also detect that after $72 \mathrm{~h}$ of treating the cells with cardanol, it causes cell cycle arrest at the G1 subphase and significant numbers of cells were death by late apoptosis $(27.2 \% \pm 1.1 \%)$, compared to a lower proportion of apoptosis ( $4.3 \pm 0.4 \%)$ and higher proportion of necrosis (35.8 $\pm 13.0 \%)$ induced by doxorubicin [56]. Along the same line of research Aru B et al. have published that propolis originated from poplar buds exerted a significant cytotoxic activity against MCF7 breast cancer and A549 lung cancer cell lines with an $\mathrm{IC}_{50}$ among 58.6-90.7 $\mu \mathrm{g} / \mathrm{mL}$, compared with Paclitaxel. Treatment with the ethanolic extract of poplar type propolis significantly decreased viability while promoting apoptosis in both cell lines. Regarding cell cycle arrest in cancer cells, MCF7 has the highest sub-G0 cell population rate [57]. This phenomenon was also observed in our study. Our data

Page $13 / 27$ 
shows that $150 \mu \mathrm{g} / \mathrm{mL}$ Pg extract induces apoptosis in a significant manner. The highest number of events was executed for the process of early apoptosis. Chicoric acid, another phenolic compound of Populus nigra L. bud obtained in this study by LC-MS analysis was reported as a chemotherapeutic agent. Tsai et al. reported that this compound $(50,150$ and $200 \mathrm{mg} / \mathrm{mL})$ induces apoptosis in HCT-116 colon cancer cell line which was described by DNA fragmentation, activation of Caspase-9 and cleavage of PARP [58]. Recently, Sun et al. has indicated that autophagy plays an important role in the progression of different diseases, especially tumors. They elucidated that chicoric acid (5, 10, 20, 40,80 and $100 \mu \mathrm{M})$ significantly reduced the SGC7901 and MGC803 human gastric cancer cell viability, prevented tumor cell growth and also induced autophagy through the activation of AMPK [59].

The excessively activated process of angiogenesis is one of the key features explaining tumor growth, highly metastatic rates and the poor prognosis of breast cancer. Natural compounds are an important source of potential multitargeted effects capable of controlling breast cancer progression [60]. Our evaluation indicated that poplar bud extracts in the concentration of $150 \mu \mathrm{g} / \mathrm{mL}$ was well tolerated, no signs of toxicity upon mucosal tissues were noted, while inducing $24 \mathrm{~h}$ after inoculation, a reduced number of newly formed vessels. Thus, indicating a potential antiangiogenic effect upon the rapid growing vascular net of the chorioallantoic membrane.

Little data is available on the effect of poplar leaf or bud extracts as angiogenic modulators. One study showed that an aqueous extract of Populus nigra L. leaves induced an activation of cutaneous angiogenesis reaction in mice induced by human mononuclear leukocytes [61]. Others have shown that extracts of poplar buds induce a vascular relaxation not related to endothelial cell activity [62]. More data regarding the angiogenesis effects is available for various poplar propolis, the most widely available type of propolis from temperate climates. The chemical profile of poplar propolis is mainly formed by flavonoids, phenylpropanoids, terpenoids, stilbenes, lignans, coumarins, with lower concentrations of phenolic acids [63]. Some types of Brazilian green propolis type, rich in artepillin C (3,5-diprenyl-4-hydroxycinnamic acid) were studied and antiangiogenic effects were recorded. Other studies on different red and green Brazilian propolis showed that polyphenols were responsible for down regulating genes involved in angiogenic signalling cascade, such as angiopoietin I, angiopoietin II, vascular endothelial growth factor (VEGF), fibroblast growth factor, metalloproteinases 2 and 9, platelet-derived growth factor, thus reducing angiogenesis and the inflammatory process [64]. Mechanistic data were reported by Kunimasa et al., showing the inference of some non-poplar Brazilian propolis extracts in inhibiting the survival signal ERK1/2 (Extracellular Signal-Regulated Kinases 1 and 2), thus inducing apoptosis that is critically involved in angiogenesis suppression [65]. Another pathway influenced by propolis as indicated by some wound healing studies is the effect on mast cells as known promoters of the angiogenesis process. Propolis decreased mast cell count and the secretion of pro-inflammatory and pro-angiogenic cytokines was therefore reduced [63]. Another study evaluated the effect Portuguese propolis on breast and prostate cancer cells and the antiproliferative effect of paclitaxel was enhanced in vitro, while reducing the neovascularization from preexisting vessels in a CAM assay, possibly due to the derivatives of caffeic acid [66].

Data on the immunomodulatory effect of the Pg extract revealed an effect of low concentrations of the extract on cytokine release by human primary dendritic cells. P35 and p19 are subunits of the IL-12 and IL-23 cytokines. P35 is forming together with p40 the cytokine IL-12, while p19 and p40 form IL-23. Both cytokines are believed to direct tumor-regulating immune responses. While IL-12 is believed to achieve an anti-tumor Th1driven inflammatory response, IL-23 is believed to favor a Th17-driven immune response [67]. Since both cytokine subunits are significantly upregulated, it is not clear which immune response will be favored by the Pg extract. From the protein data in this study, it was clear, that IL-23 release was slightly upregulated by the extract. IL-12 measurement failed in our experiments, since levels were under the limit of quantification. On the other hand, IL-10 levels were slightly increased as well. IL-10 is known to have a suppressive effect on the immune system being an important regulator of immune tolerance [68]. It thus needs to be elucidated in which direction the Pg extract will drive immunomodulation or if a general activation of the immune response is achieved by the phytocompound.

The increase in cell toxicity and the development of apoptotic processes in the presence of higher Pg extract concentrations is indicated by the constantly decreased release of cytokines with rising amounts of the extract. Apoptosis staining confirmed these results.

\section{Conclusion}

To the best of our knowledge this is the first comprehensive study that includes data regarding both the antioxidant activity,along with the biological activity of poplar bud extract obtained from the western part of Romania on breast adenocarcinoma and dendritic cells. The extract has inhibitory activity against Gram-positive bacteria, Streptococcus pyogene and Streptococcus mutans, followed by Staphylococcus aureus. The comprehensive assessment of the effect of Pg extract against MCF7 human breast cancer cell line indicates that under experimental conditions, the extract may exert an anticancer effect through the inhibition of cell proliferation and migration and the induction of early apoptotic events. Moreover, the extract showed antiangiogenic potential on the chorioallantoic membrane. In low concentrations, the Pg extract has also an immunomodulatory potential on human primary dendritic cells.

\section{Abbreviations}

AOA, Antioxidant activity; ATCC, American Type Culture Collection; BAX, Apoptosis regulator; BCL-2, B-cell lymphoma 2; BF, Bright field; CAM, Chorioallantoic membrane; CCE, Chlorogenic acid equivalent; CFU, Colony forming units; CLSI, Clinical Laboratory and Standard Institute; DAPI, 
4',6-diamidino-2- phenylindole; DCs, Dendritic cells; DMSO, Dimethyl sulfoxide; DNA, Deoxyribonucleic acid; DPPH, 2,2-diphenyl-1-picrylhydrazyl; EDD, Embryonic day of development; ERK1/2, Extracellular Signal-Regulated Kinases 1 and 2; ESI-MS, Electrospray ionization coupled with mass spectrometry; EUCAST, European Committee on Antimicrobial Susceptibility Testing; FBS, Fetal bovine serum; FT-IR, Fourier-transform infrared spectroscopy; GABAB, Gamma-aminobutyric acid; HGF-1, Insulin-like growth factor 1; HPLC, high-performance liquid chromatography; IC50, Halfmaximal inhibitory concentration; LC, Liquid chromatography; LDH, Lactate Dehydrogenase; IL, Interleukin; LPS, Lipopolysaccharide; MIC, Minimum inhibitory concentration; MBC, Minimum bactericidal concentration; MH, Mueller Hinton; mRNA, messenger Ribonucleic acid; MS, Mass spectrometry; MTT, 3-(4,5-dimethylthiazol-2-yl)-2,5-diphenyltetrazolium bromide; NF-KB, Nuclear factor kappa B; PARP, Poly ADP-ribose polymerase; PBMCs, Primary peripheral blood mononuclear cells; PBS, Phosphate Buffer Saline; Pg, Populus nigra L. bud extract; PI, Propidium iodide; Rt, Retention time; TG-DSC, Thermogravimetric Analysis-Differential Scanning Calorimetry; TNF-a, Tumor necrosis factor alpha; UV-VIS, Ultraviolet visible; VEGF, Vascular endothelial growth factor.

\section{Declarations}

\section{Ethics and Consent to Participate}

Not applicable. The study does not involve testing on animals or humans.

The collection of the wild plant samples (poplar buds,specimen number Pg 3/2019) complies with the Pharmacognosy department's guidelines ( Faculty of Pharmacy,"Victor Babes University of Medicine and Pharmacy",Romania). The procedure for sample collection, preservation, and laboratory analysis was reviewed by the members of the department to ensure that there is compliance.

\section{Consent to Publish}

All authors have approved the manuscript, its content and submission to the journal.

\section{Funding}

This research was funded by “Victor Babes” University of Medicine and Pharmacy, grant number 3POSTDOC/1238/2020 offered to Prof. PhD. Pharm. Corina Danciu.

\section{Availabilityofdata and materials}

All data used to support the findings of this study are

included within the article.

\section{Competinginterests}

Theauthorsdeclare that theyhave nocompetinginterests.

\section{Consentforpublication}

All authors have agreed to be so listed and have seen and approved the manuscript.

\section{Acknowledgements}

Not applicable.

\section{Authors'contributions}

Conceptualization, B.K., I.Z.P., D.M. (Delia Muntean) and C.D.; extract preparation, D.M. (Daliana Minda); phytochemical analysis, Z.D.; antioxidant activity, E.A.M., D.M. (Daliana Minda); physicochemical screening, E.A.M; antimicrobial activity, D.M. (Delia Muntean); cytotoxic activity, B.K., I.Z.P., M.H.S.J., A.S., C.O., F.B.; angiogenesis, S.A.; immunomodulatory activity, M.H.S.J., A.S., H.H.R.; resources, C.D.; writing-original draft preparation, B.K., I.Z.P., S.A., E.A.M., M.H.S.J., A.S., D.M., Z.D., D.M., C.O., C.D.; writing-review and editing, H.H.R., C.A.D., C.S., and C.D.; validation, H.H.R., C.A.D., C.S., and C.D.; visualization, H.H.R., F.B., C.A.D. and C.S.; supervision, C.D.; project administration, C.D., I.Z.P.; funding acquisition, C.D. All authors have read and agreed to the published version of the manuscript.

\section{References}

1. Karrenberg, S., Edwards, P. J., Kollmann, J., 2002. The life history of Salicaceaeliving in the active zone of floodplains. Freshwater Biology 47, 733-748. doi: https://doi.org/10.1046/j.1365-2427.2002.00894.x 
2. Stănescu, U., Hăncianu, M., Cioancă, O., Aprotosoaie, A.C., Miron, A., 2018. Plante medicinale de la A la Z, ed. a III-a, revizuită şi adăugită, Editura Polirom, laşi. ISBN 978-973-46-7240-0.

3. Lee, Y. S., Cui, C. B., Kim, J. K., Bae, Y. S., Lee, J. Y., Kang, I. J., Lim, S. S., 2010. Inhibitory Effect of Populoside from the Bark of Populus nigra on Aldose Reductase. J. Korean Soc. Appl. Biol. Chem. 53, 729-733. doi: 10.3839/jksabc.2010.110

4. Stănescu, U., Hăncianu, M., Gîrd, C.E., 2020. Farmacognozie. Produse vegetale cu substanțe bioactive. Editura Polirom, lasi, Romania. ISBN978-973-46-7996-6

5. Isidorov, V.A., Vinogorova, V.T., 2003. GC-MS analysis of compounds extracted from buds of Populus balsamifera and Populus nigra. Z. Naturforsch. 58, 355- doi: 10.1515/znc-2003-5-612.

6. Ristivojević, P., Trifković, J., Andrić, F., Milojković-Opsenica, D., 2015. Poplar-type propolis: Chemical composition, botanical origin and biological activity. Nat. Prod. Commun. 10, 1869-76. doi: 10.1177/1934578X1501001117.

7. Jerković, I., Mastelić, J., 2003. Volatile compounds from leaf-buds of Populus nigra L. (Salicaceae). Phytochemistry 63, 109-113. doi: 10.1016/S0031-9422(02)00706-9

8. Ram, A., Balachandar, S., Vijayananth, P., Singh, V. P., 2011. Medicinal plants useful for treating chronic obstructive pulmonary disease (COPD): Current status and future perspectives. Fitoterapia 82, 141-151. doi: 10.1016/j.fitote.2010.09.005.

9. Todaro, L., Russo, D., Cetera, P., Milella, L., 2017. Effects of thermo-vacuum treatment on secondary metabolite content and antioxidant activity of poplar (Populus nigra L.) wood extracts. Ind. Crops Prod. 109, 384-390. doi: 10.1016/j.indcrop.2017.08.052.

10. Conte, R., Gullich L. M. D., Filippi, D., Pazinatto, C. A., Bilibio, D., Carniel, N., Mazutti, M., Wagner L. P., Bender, J. P., 2016. Ultrasound-Assisted Extraction of Total Polyphenols from Black Poplar (Populus nigra L.) and Evaluation of Antioxidant Potential. Indian J. Adv. Chem. 4, 25-30.

11. Iori, V., Pietrini, F., Zacchini, M., 2012. Assessment of ibuprofen tolerance and removal capability in Populus nigra L. by in vitro culture. J. Hazard. Mater. 229-230, 217-223. doi: 10.1016/j.jhazmat.2012.05.097.

12. Dimkić, I., Ristivojević, P., Janakiev, T., Berić, T., Trifković, J., Milojković-Opsenica, D., Stanković, S., 2016. Phenolic profiles and antimicrobial activity of various plant resins as potential botanical sources of Serbian propolis. Ind. Crop. Prod. 94, 856-871. doi: 10.1016/j.indcrop.2016.09.065.

13. Vardar-Unlu, G., Silici, S., Unlu, M., 2008. Composition and in vitro antimicrobial activity of Populus buds and poplar-type propolis. World J. Microbiol. Biotechnol. 24, 1011-1017. doi: 10.1007/s11274-007-9566-5.

14. Pobłocka-Olech, L., Migas, P., Krauze-Baranowska, M., 2018. TLC determination of some flavanones in the buds of different genus Populus species and hybrids. Acta Pharm. 68, 199-210. doi: 10.2478/acph-2018-0018.

15. Wang, K., Zhang, J., Ping, S., 2014. Anti-inflammatory effects of ethanol extracts of Chinese propolis and buds from poplar (Populus×canadensis). J. Ethnopharmacol. 155, 300-311. doi: 10.1016/j.jep.2014.05.037.

16. Manzocco, L., Anese, M., Nicoli, M. C., 1998. Antioxidant properties of tea extracts as affected by processing. LWT- Food Science and Technology 31, 694-698. doi: 10.1006/FSTL.1998.0491.

17. Moacă, E.A., Farcaş, C., Ghiţu, A., Coricovac, D., Popovici, R., Cărăba-Meiţă, N. L., Ardelean, F., Antal, D.S., Dehelean, C., Avram, Ş., 2018. Comparative Study of Melissa officinalis Leaves and Stems Ethanolic Extracts in terms of Antioxidant, Cytotoxic, and Antiproliferative Potential. Evid. Based Complement. Alternat. Med. 2018, 1-12. doi: 10.1155/2018/7860456.

18. Easmin, S., Sarker, M.Z.I., Ghafoor, K., Ferdosh,S., Jaffri, J., EaqubAli, Md., Mirhosseini, H., Al-Juhaimi, F.Y., Perumal, V., Khatib, A., 2017. Rapid investigation of a-glucosidase inhibitory activity of Phaleria macrocarpa extracts using FTIR-ATR based fingerprinting. J. Food Drug Anal. 25, 306-315. doi: 10.1016/j.jfda.2016.09.007.

19. Fernández, J. M., Plaza, C., Polo, A., Plante, A. F., 2012. Use of thermal analysis techniques (TG-DSC) for the characterization of diverse organic municipal waste streams to predict biological stability prior to land application. Waste Manage. 32, 158-164. doi: 10.1016/j.wasman.2011.08.011.

20. Arendrup, M. C., Cuenca-Estrella, M., Lass-Flörl, C., Hope, W., EUCAST-AFST., 2012. Eucast technical note on the EUCAST definitive document EDef 7.2: Method for the determination of broth dilution minimum inhibitory concentrations of antifungal agents for yeasts EDef 7.2. Clin. Microbiol. Infect. 18, 246-247. doi: 10.1111/j.1469-0691.2012.03880.x

21. Clinical and Laboratory Standards Institute. Methods for Dilution Antimicrobial Susceptibility Tests for Bacteria That Grow Aerobically, 2018, 11th ed.; CLSI standard M07; Wayne, PA: Clinical and Laboratory Standards Institute, USA.

22. Buda, V., Brezoiu, A.M., Berger, D., Pavel, I.Z., Muntean, D., Minda, D., Dehelean, C. A., Soica, C., Diaconeasa, Z., Folescu, R., Danciu, C., 2020. Biological Evaluation of Black Chokeberry Extract Free and Embedded in Two Mesoporous Silica-Type Matrices. Pharmaceutics 12, 838. doi: https://doi.org/10.3390/pharmaceutics12090838.

23. Muntean, D., Licker, M., Alexa, E., Popescu, I., Jianu, C., Buda, V., Dehelean, C. A., Ghiulai, R., Horhat, F., Horhat, D., Danciu, C., 2019. Evaluation of essential oil obtained from Menthaxpiperita L. against multidrug-resistant strains. Infect. Drug Resist. 12, 2905-2914. doi: 10.2147/IDR.S218141. 
24. Nair, S., Archer, G.E., Tedder, T.F., 2012. Isolation and generation of human dendritic cells. Curr Protoc Immunol. Chapter 7, Unit7.32. doi: 10.1002/0471142735.im0732s99.

25. Ghițu, A., Schwiebs, A., Radeke, H. H., Avram, S., Zupko, I., Bor, A., Pavel, I. Z., Dehelean, C. A., Oprean, C., Bojin, F., Farcas, C., Soica, C., Duicu, O., Danciu., 2019. A Comprehensive Assessment of Apigenin as an Antiproliferative, Proapoptotic, Antiangiogenic and Immunomodulatory Phytocompound. Nutrients 11, 858. doi: 10.3390/nu11040858.

26. Moacă, E.A., Pavel, I.Z., Danciu, C., Crăiniceanu, Z., Minda, D., Ardelean, F., Antal, D.S., Ghiulai, R., Cioca, A., Derban, M., Simu, S., Chioibaş, R., Szuhanek, C., Dehelean, C.A., 2019. Romanian Wormwood (Artemisia absinthium L.): Physicochemical and Nutraceutical Screening. Molecules. 24, 3087, doi: 10.3390/molecules24173087.

27. Avram, S., Coricovac, D. E., Pavel, I. Z., Pinzaru, I., Ghiulai, R., Baderca, F., Soica, C., Muntean, D., Branisteanu, D. E., Spandidos, D. A., Tsatsakis, A. M., Dehelea, C. A., 2017. Standardization of A375 human melanoma models on chicken embryo chorioallantoic membrane and Balb/c nude mice. Oncology Reports, 38, 89-99. doi: https://doi.org/10.3892/or.2017.5658.

28. Diaconeasa, Z., luhas, C.I., Ayvaz, H., Rugină, D., Stanilă, A., Dulf, F., Bunea, A., Socaci, S.A., Socaciu, C., Pintea, A., 2019. Phytochemical Characterization of Commercial Processed Blueberry, Blackberry, Blackcurrant, Cranberry, and Raspberry and Their Antioxidant Activity. Antioxidants 8, 540, 1-15. doi: 10.3390/antiox8110540.

29. Rubiolo, P., Casetta, C., Cagliero, C., Brevard, H., Sgorbini, B., Bicchi, C., 2013. Populus nigra L. bud absolute: a case study for a strategy of analysis of natural complex substances. Analytical and Bioanalytical Chemistry 405, 1223-1235. doi: 10.1007/s00216-012-6537-y.

30. Swinney, D. C., 2011. Molecular Mechanism of Action (MMoA) in Drug Discovery. Ann. Rep. Med. Chem. 301-317. doi:10.1016/b978-0-12386009-5.00009-6.

31. Characteristic of IR Absorption Frequencies of Organic Functional Groups. Available at: http://www2.ups.edu/faculty/hanson/Spectroscopy/IR/IRfrequencies.html (Accessed on 02.12.2020)

32. Lisperguer, J., Saravia, Y., Vergara, E., 2016. Structure and thermal behavior of tannins from acacia dealbata bark and their reactivity toward formaldehyde. J. Chil. Chem. Soc. 61, 3188-3190. doi: 10.4067/S0717-97072016000400007.

33. Ribatti D., 2010. The Chick Embryo Chorioallantoic Membrane in the Study of Angiogenesis and Metastasis. Springer 130.

34. Kis, B., Pavel, I.Z., Haidu, D., Ștefănuț, M.N., Diaconeasa, Z., Moacă, E.A., Dehelean, C.A., Șipos, S., Ivan, A., Danciu, C. Inorganic Element Determination of Romanian Populus nigra Buds Extract and In Vitro Antiproliferative and Pro-Apoptotic Evaluation on A549 Human Lung Cancer Cell Line. Pharmaceutics. 2021 Jun 29;13:986. doi: 10.3390/pharmaceutics13070986.

35. Greenaway, W., May, J., Scaysbrook, T., Whatley, F.R., 1991. Identification by gas chromatography-mass spectrometry of 150 compounds in propolis. Z. Naturforsch. Sect. C J. Biosci. 46, 111-121.

36. Merghache, D., Boucherit-Otmani Z., El Haci I., Merghachec, S., Chikhid, I., Boucherita, K., 2016. Antioxidant and antimicrobial activities of algerian Populus nigra L. buds extracts. Braz. J. Pharm. Sci. 3, 1-8. doi: 10.5121/bioej.2016.3201.

37. Dudonné, S., Poupard, P., Coutière, P., Woillez, M., Richard, T., Merillon, J. M., Vitrac, X., 2011. Phenolic composition and antioxidant properties of poplar bud (Populus nigra L.) extract: individual antioxidant contribution of phenolics and transcriptional effect on skin aging. J. Agric. Food Chem. 59, 4527-4536. doi: https://doi.org/10.1021/jf104791t.

38. Mainar, A. M., Langa, E., Berrueco, B., Maestro, C., Urieta, J. S., 2008. Antioxidant Activity of Supercritical Extracts of Populus Buds. 11th Eur Meet Supercrit Fluids New Perspect Supercrit Fluids Nanosci Mater Process 2-7.

39. Debbache, N., Atmani, D., Atmani, D., 2014. Chemical analysis and biological activities of Populus nigra, flower buds extracts as source of propolis in Algeria. Ind. Crops Prod. 53, 85-92. doi: 10.1016/j.indcrop.2013.12.018

40. Szymczycha-Madeja, A., Welna, M., Zyrnicki, W., 2013. Multi-element analysis, bioavailability and fractionation of herbal tea products. J. Braz. Chem. Soc. 24, 777-787. doi: https://doi.org/10.5935/0103-5053.20130102.

41. Mohani, N., Ahmad, M., Mehjabeen, Jahan, N., 2014. Evaluation of phytoconstituents of three plants Acorus calamus linn. Artemisia absinthium Linn and Bergenia himalaica boriss by FTIR spectroscopic analysis. Pak. J. Pharm. Sci. 27, 2251-2255.

42. Li, Y.Q., Kong, D.X., Wu, H., 2013. Analysis and evaluation of essential oil components of cinnamon barks using GC-MS and FTIR spectroscopy. Ind. Crops Prod. 41, 269-278. doi: 10.1016/j.indcrop.2012.04.056.

43. Heredia-Guerrero, J.A., Benítez, J.J., Domínguez, E., Bayer, I.S., Cingolani, R., Athanassiou, A., Heredia, A., 2014. Infrared and Raman spectroscopic features of plant cuticles: A review. Front. Plant Sci. 5, 305. doi: https://doi.org/10.3389/fpls.2014.00305.

44. Toiu, A., Vlase, L., Oniga, I., Benedec, D., Tămaş, M., 2011. HPLC analysis of salicylic derivatives from natural products. Farmacia 59, $106-112$.

45. Cheng, Y., Xu, Q., Liu, J., Zhao, C., Xue, F., Zhao, Y., 2014. Decomposition of five phenolic compounds in high temperature water. J. Braz. Chem. Soc. 25, 2012-2017. doi: https://doi.org/10.5935/0103-5053.20140201.

46. Chaaban, H., Ioannou, I., Chebil, L., Slimane, M., Gérardin, C., Paris, C., Charbonnel C., Chekir, L., Ghoul, M., 2017. Effect of heat processing on thermal stability and antioxidant activity of six flavonoids. J. Food Proces. Preser. 41. doi: https://doi.org/10.1111/jfpp.13203.

47. Kis, B., Avram, S., Pavel, I.Z., Lombrea, A., Buda, V., Dehelean, C. A., Soica, C., Yerer, M.B., Bojin, F., Folescu, R., Danciu, C., 2020. Recent Advances Regarding the Phytochemical and Therapeutic Uses of Populus nigra L. buds. Plants 9, 1464. doi: https://doi.org/10.3390/plants9111464.

Page $17 / 27$ 
48. Boumghar, N., Behidj, N., Ksouri, R., 2019. Antimicrobial and antibiofilm activities of phenolic compounds extracted from Populus nigra L. and Populus alba L. buds (Algeria). J. Pharm. Sci. 55, 18114. doi: http://dx.doi.org/10.1590/s2175-97902019000218114.

49. De Marco, S., Piccioni, M., Pagiotti, R., Pietrella, D., 2017. Antibiofilm and Antioxidant Activity of Propolis and Bud Poplar Resins versus Pseudomonas aeruginosa. Evid. Based. Complement. Alternat. Med. 2017, 1-11. doi: https://doi.org/10.1155/2017/5163575.

50. Benedec, D., Oniga, I., Muresan, B., Mot, A.C., Damian, G., Nistor, A., Silaghi-Dumitrescu, R., Hanganu, D., Duma, M., Vlase, L., 2014. Contrast between Water- and Ethanol-Based Antioxidant Assays. J. Food Qual. 37, 259-267. doi: 10.1111/jfq.12090.

51. Sukardiman, A., Widyawaruyanti, A., Widyowati, R., Sismindari, Zaini, N.C., 2014. Pinostrobin isolated from Kaempferia pandurata Roxb induced apoptosis in t47d human breast cancer cell line. E-Journal Planta Husada 2, 20-6.

52. Jaudan, A., Sharma, S., Malek, S.N.A., Dixit, A., 2018. Induction of apoptosis by pinostrobin in human cervical cancer cells: Possible mechanism of action. PLoS One. 13, 1-23. doi: https://doi.org/10.1371/journal.pone.0191523.

53. Zheng, Y., Wang, K., Wua, Y., Chena, Y., Chena, X., Huc, C.W., Hua, F., 2018. Pinocembrin induces ER stress mediated apoptosis and suppresses autophagy in melanoma cells. Cancer Lett. 431, 31-42. doi: 10.10

54. Cao, X., Liu, B., Cao, W., Zhang, W., Zhang, F., Zhao, H., Meng, R., Zhang, L., Niu, R., Hao, X., Zhang, B., 2013. Autophagy inhibition enhances apigenin-induced apoptosis in human breast cancer cells. Chin. J. Cancer Res. 25, 212-222. doi: 10.3978/j.issn.1000-9604.2013.04.01.

55. Gao, J., Lin, S., Gao, Y., Zoua, X., Zhub, J., Chenc, M., Wana, H.; Zhua, H., 2019. Pinocembrin inhibits the proliferation and migration and promotes the apoptosis of ovarian cancer cells through down-regulating the mRNA levels of N-cadherin and GABAB receptors. Biomed. Pharmacother. 120, 109505. doi: 10.1016/j.biopha.2019.109505.

56. Buahorm, S., Puthong, S., Palaga, T., Lirdprapamongkol, K., Phuwapraisirisan, P., Svasti, J., Chanchao, C., 2015. Cardanol isolated from Thai Apis mellifera propolis induces cell cycle arrest and apoptosis of BT-474 breast cancer cells via p21 upregulation. DARU Journal of Pharmaceutical Sciences 23. doi: 10.1186/s40199-015-0138-1.

57. Aru, B.; Güzelmeric, E., Akgül, A., Demirel, G. Y., Kırmızıbekmez, H., 2019. Antiproliferative Activity of Chemically Characterized Propolis from Turkey and Its Mechanisms of Action. Chem. Biodivers. 16, e1900189. doi: 10.1002/cbdv.201900189.

58. Tsai, Y. L., Chiu, C. C., Yi-Fu Chen, J., Chan, K. C., Lin, S.D., 2012. Cytotoxic effects of Echinacea purpurea flower extracts and cichoric acid on human colon cancer cells through induction of apoptosis. J. Ethnopharmacol. 143, 914-919. doi: 10.1016/j.jep.2012.08.032

59. Sun, X., Zhang, X., Zhai, H., Zhang, D. Ma, S., 2019. Chicoric acid (CA) induces autophagy in gastric cancer through promoting endoplasmic reticulum (ER) stress regulated by AMPK. Biomed. Pharmacother. 118, 10914. doi: 10.1016/j.biopha.2019.109144.

60. Ghiulai, R., Avram, S., Stoian, D., Pavel, I.Z., Coricovac, D., Oprean, C., Vlase, L., Farcas, C., Mioc, M., Minda, D., Motoc, A., Szuhanek, C., Danciu, C., Soica, C., Sima, L., 2020. Lemon Balm Extracts Prevent Breast Cancer Progression in Vitro and in Ovo on Chorioallantoic Membrane Assay. Evid. Based Complement. Altern. Med. 2020, 6489159. doi: 10.1155/2020/6489159.

61. Glinkowska, G., Bałan, B., Sommer, E., Demkow, U., Sokolnicka, I., Strzelecka, H., Skopińska-Rózewska, E., 1997. The effect of phenolic compounds of poplar leaves extract on cutaneous angiogenesis reaction induced in mice by human mononuclear leukocytes. Acta Pol. Pharm. 54, 151-154.

62. Debbache-Benaida, N., Atmani-Kilani. D., Schini-Keirth, V.B., Djebbli, N., Atmani, D., 2013. Pharmacological potential of Populus nigra extract as antioxidant, anti-inflammatory, cardiovascular and hepatoprotective agent. Asian Pac. J. Trop. Biomed. 3 (9), 697-704, doi: 10.1016/S22211691(13)60141-0.

63. Oryan, A., Alemzadeh, E., Moshiri, A., 2018. Potential role of propolis in wound healing: Biological properties and therapeutic activities. Biomed. Pharmacother. 98, 469-483. doi: 10.1016/j.biopha.2017.12.069.

64. Daleprane, J.B., Abdalla, D.S., 2013. Emerging roles of propolis: Antioxidant, cardioprotective, and antiangiogenic actions. Evid. Based Complement. Altern. Med. 2013, 175135. doi: 10.1155/2013/175135.

65. Kunimasa, K., Ahn, M. R., Kobayashi, T., Eguchi, R., Kumazawa, S., Fujimori, Y., Nakano, T., Nakayama, T., Kaji, K., Ohta, T., 2011. Brazilian propolis suppresses angiogenesis by inducing apoptosis in tube-forming endothelial cells through inactivation of survival signal ERK1/2. Evid. Based Complement. Altern. Med. 2011, 870753. doi: 10.1093/ecam/nep024.

66. Silva-Carvalho, R., Miranda-Gonçalves, V., Ferreira, A. M., Cardoso, S. M., Sobral, A. J. F. N., Almeida-Aguiar, C., Baltazar, F., 2014. Antitumoural and antiangiogenic activity of Portuguese propolis in in vitro and in vivo models. J. Funct. Foods. 11, 160-171. doi: https://doi.org/10.1016/j.jff.2014.09.009.

67. Chyuan, I.T., Lai, J.H., 2020. New insights into the IL-12 and IL-23: From a molecular basis to clinical application in immune-mediated inflammation and cancers. Biochem Pharmacol. 175, 113928. doi: 10.1016/j.bcp.2020.113928.

68. Taylor, A., Verhagen, J., Blaser, K., Akdis, M., Akdis, C.A., 2006. Mechanisms of immune suppression by interleukin-10 and transforming growth factor-beta: the role of T regulatory cells. Immunology. 117, 433-442. doi: 10.1111/j.1365-2567.2006.02321.x

\section{Figures}




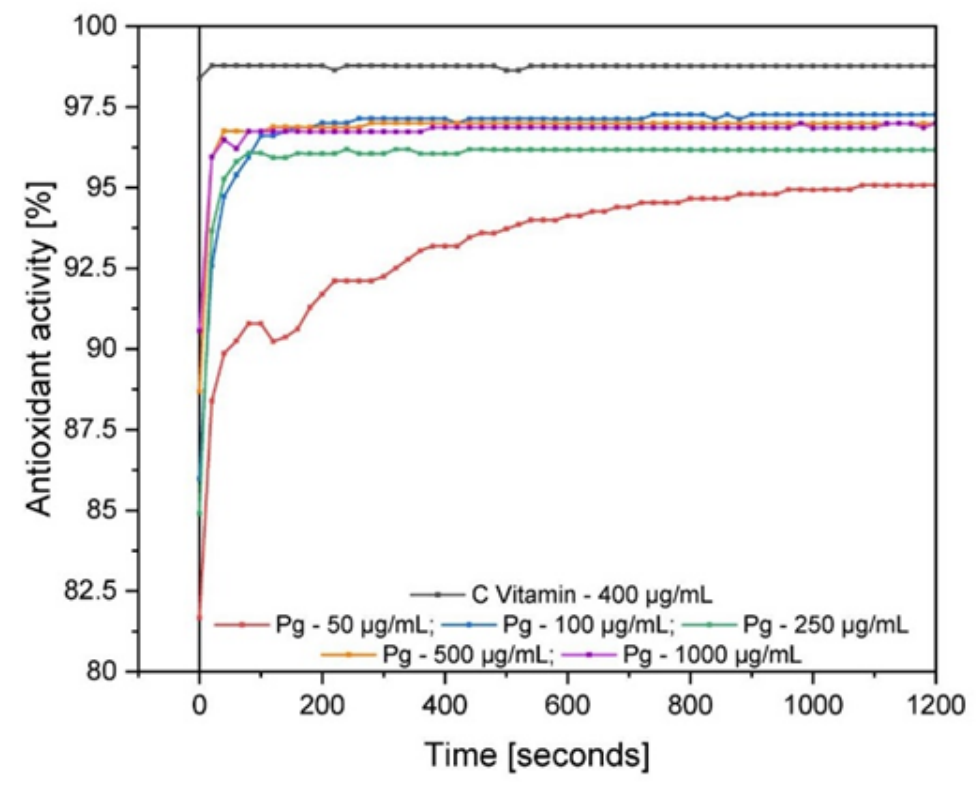

Figure 1

AOA of Pg extracts $(50,100,250,500,1000 \mu \mathrm{g} / \mathrm{mL})$ compared to ascorbic acid $(400 \mu \mathrm{g} / \mathrm{mL})$.

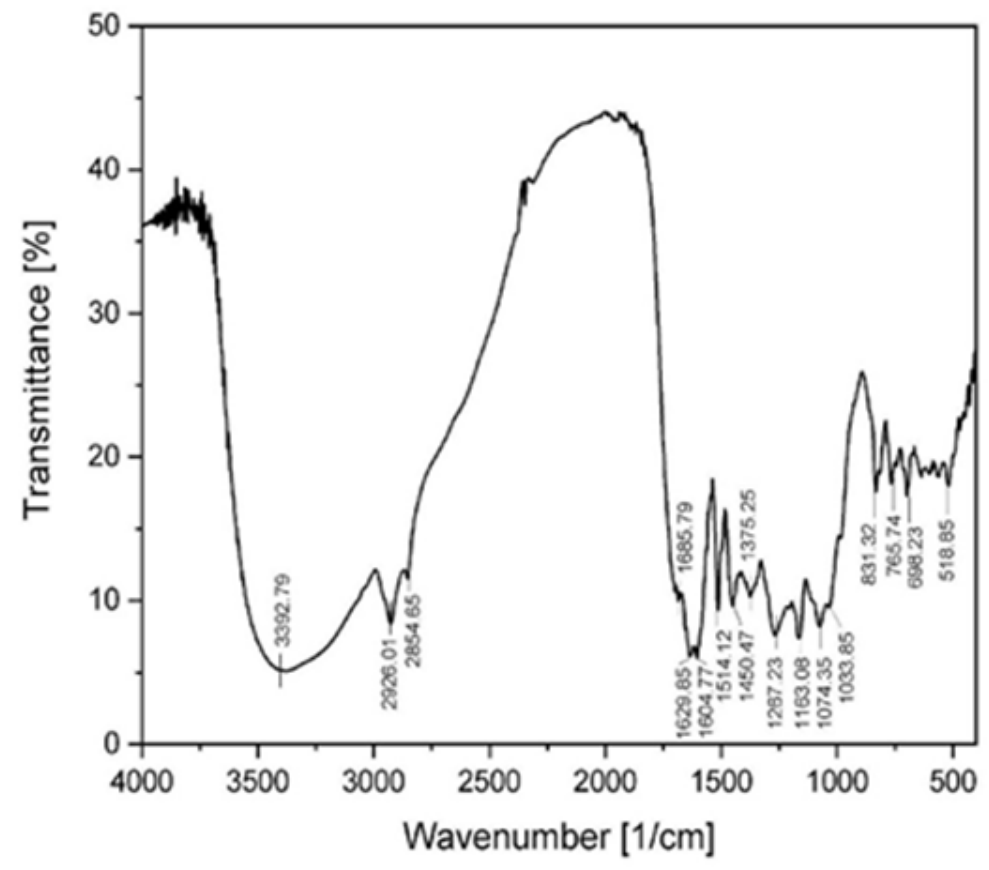

Figure 2

FT-IR spectra of Pg extract. 


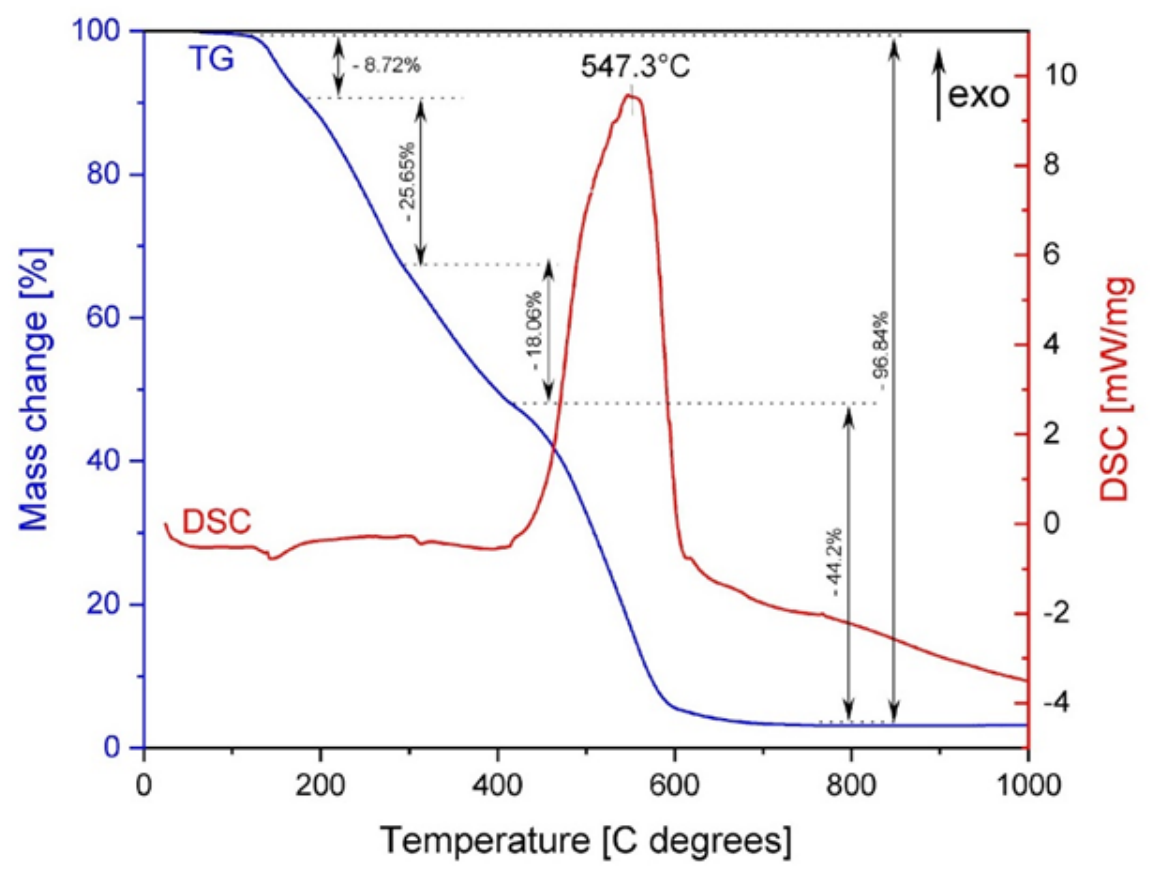

Figure 3

TG-DSC curves of Pg (aqueous, alcoholic, hydro-alcoholic) extract.

MCF7- human breast adenocarcinoma

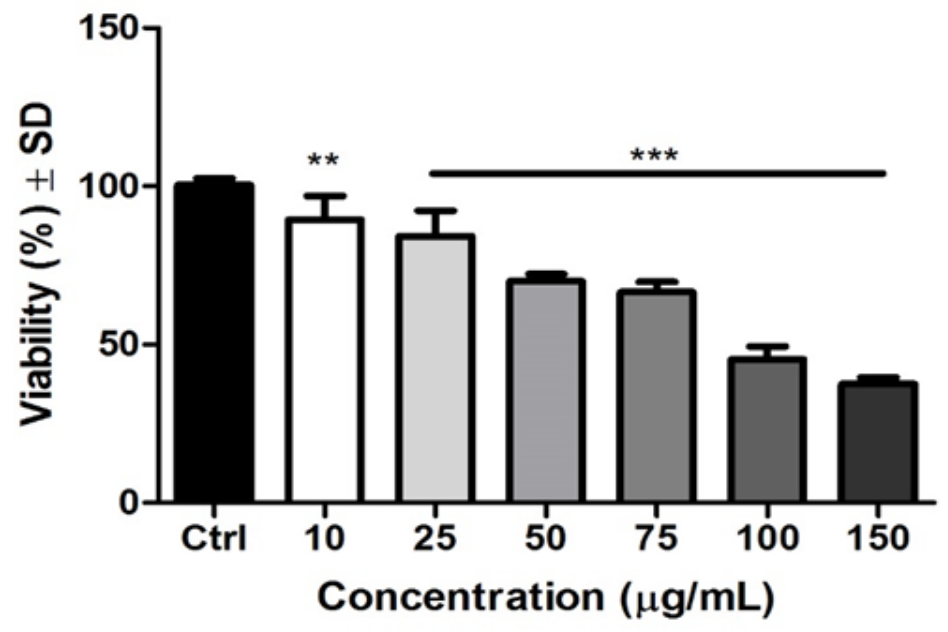

Figure 4

MCF7 human breast adenocarcinoma cells viability after $72 \mathrm{~h}$ stimulation with $\mathrm{Pg}(10,25,50,75,100$ and $150 \mu \mathrm{g} / \mathrm{mL})$. The results are expressed as cell viability percentage (\%) related to the Control cells. Comparison among groups was made using One-way ANOVA test and Dunnett's multiple comparison post-test. (** $\mathrm{p}<0.01 ; * \star * \mathrm{p}<0.001$ vs. Control). 
MCF-10A - human breast epithelial cells

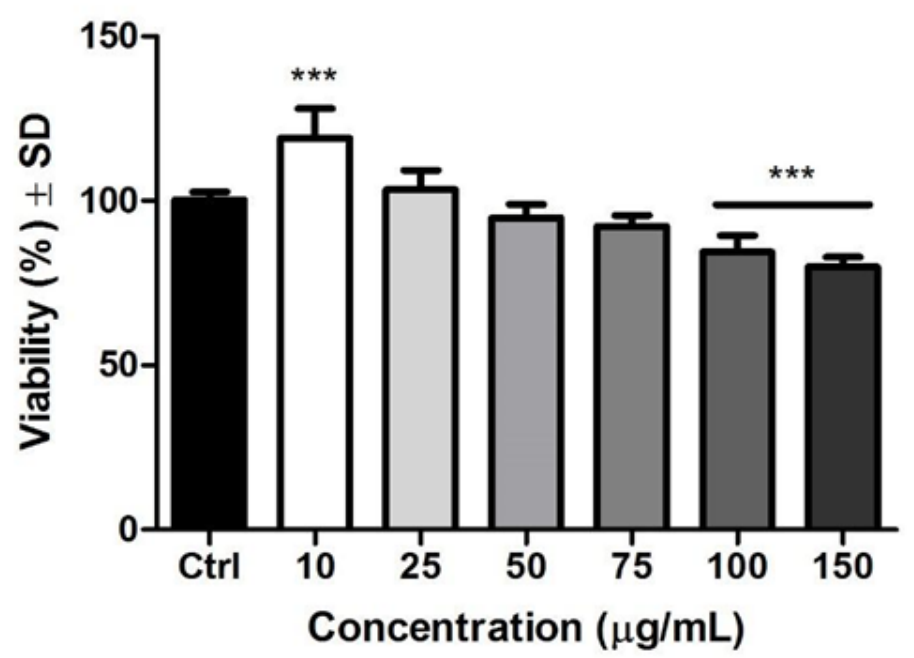

Figure 5

MCF-10A human breast epithelial cells viability after $72 \mathrm{~h}$ stimulation with $\mathrm{Pg}(10,25,50,75,100$ and $150 \mu \mathrm{g} / \mathrm{mL})$. The results are expressed as cell viability percentage (\%) related to the Control cells. Comparison among groups was made using One-way ANOVA test and Dunnett's multiple comparison post-test. (*** $\mathrm{p}<0.001$ vs. Control).

MCF7- human breast adenocarcinoma

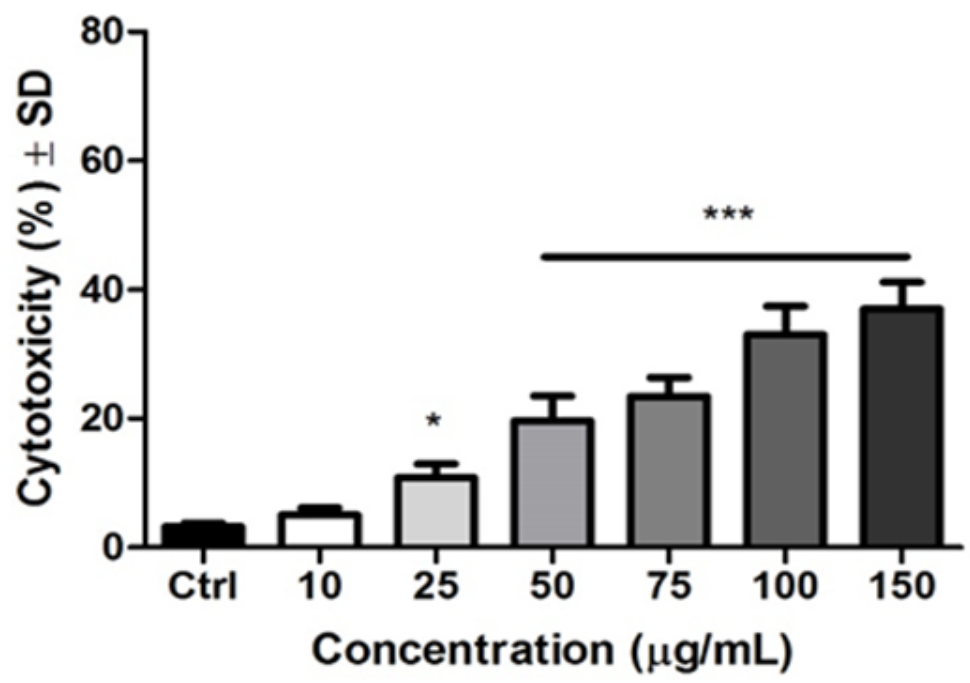

Figure 6

The cytotoxic effect of $\mathrm{Pg}(10,25,50,75,100$ and $150 \mu \mathrm{g} / \mathrm{mL})$ on MCF7 human breast adenocarcinoma cells after $72 \mathrm{~h}$ stimulation. The results are expressed as cytotoxicity percentage (\%) related to the Control cells. Comparison among groups was made using One-way ANOVA test and Dunnett's multiple comparison post-test. (* $p<0.05$; ** $p<0.001$ vs. Control). 
Control

Oh

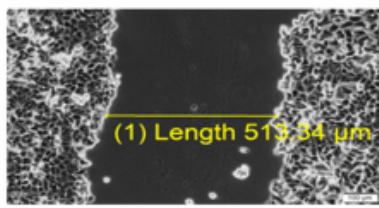

$24 \mathrm{~h}$

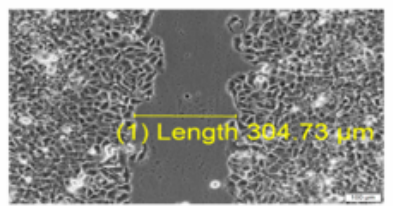

Control

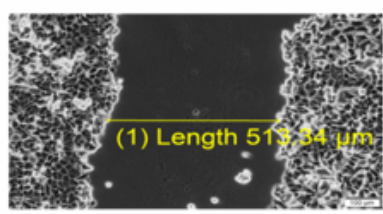

$24 h$

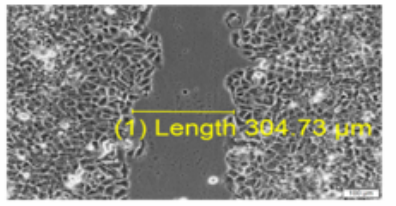

Pg 10 ug $/ \mathrm{mL}$
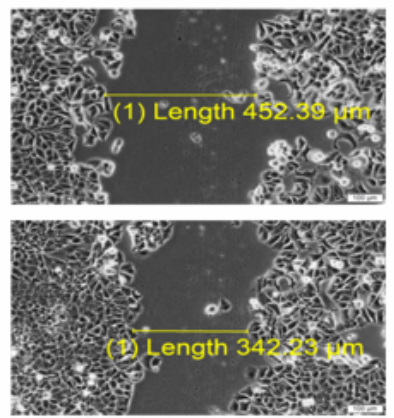

Pg 75 ug/mL
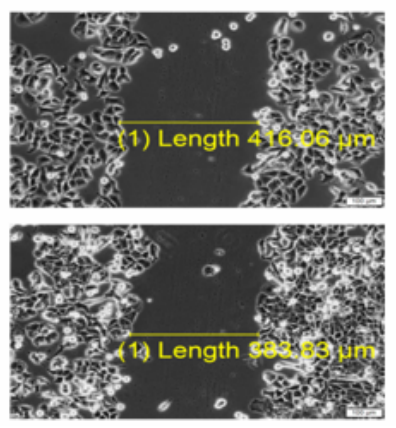

MCF7 cell line

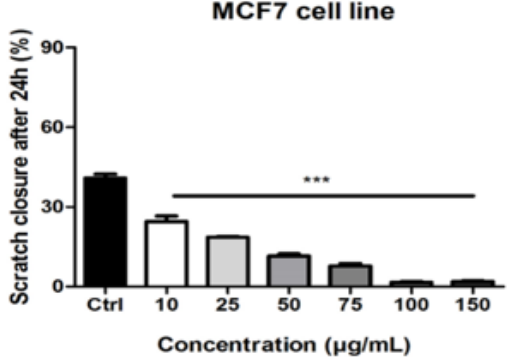

$\mathrm{Pg} 25$ ug/mL
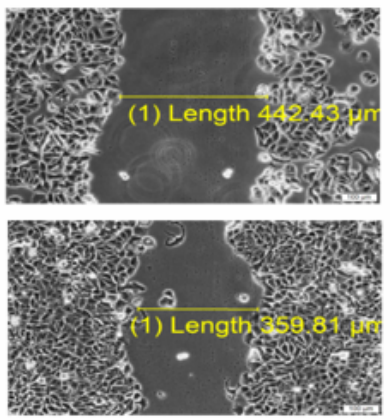

Pg 100 ug $/ \mathrm{mL}$
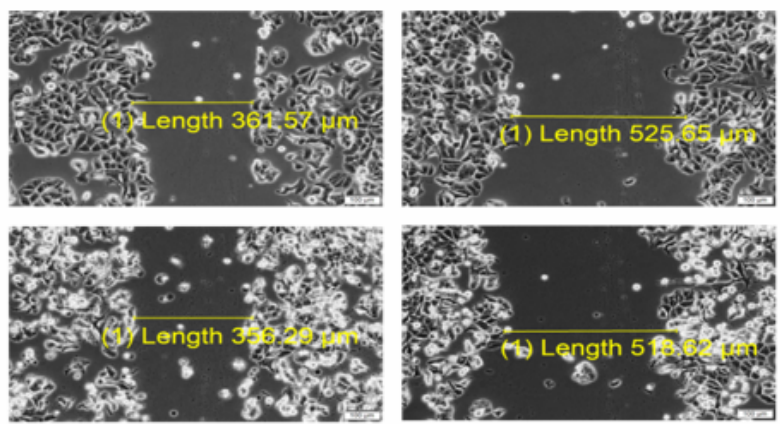

(c)
Pg 50 ug/mL
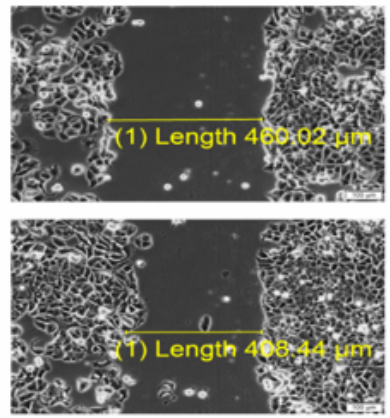

Pg 150 ug $/ \mathrm{mL}$

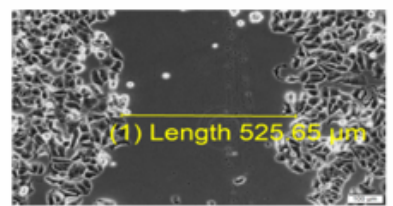

(b)

\section{Figure 7}

a) Pg extract (10, 25, and $50 \mu \mathrm{g} / \mathrm{mL}$ ) activity on MCF7 human breast adenocarcinoma cells migration and proliferation potential. Progression of cell migration was monitored by imaging the scratch line initially and at $24 \mathrm{~h}$ post-stimulation. Images were taken by light microscopy at $10 \times$ magnification; (b) Pg extract (75, 100, and $150 \mu \mathrm{g} / \mathrm{mL}$ ) activity on MCF7 human breast adenocarcinoma cells migration and proliferation potential; (c) The anti-migratory potential of Pg extract $(10,25,50,75,100$ and $150 \mu \mathrm{g} / \mathrm{mL})$ on MCF7 breast adenocarcinoma cells. The bar graphs are expressed as percentage of scratch closure after $24 \mathrm{~h}$ compared to the initial surface. Comparison among groups was made using One-way ANOVA test and Dunnett's multiple comparison post-test. ( ${ }^{\star \star \star} p<0.001$ vs. Control). 


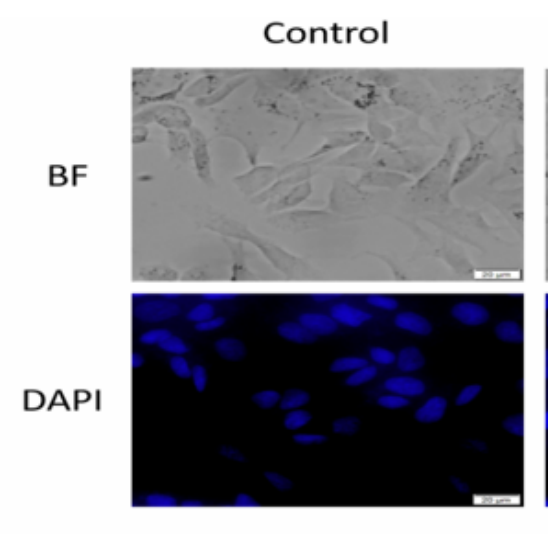

Control

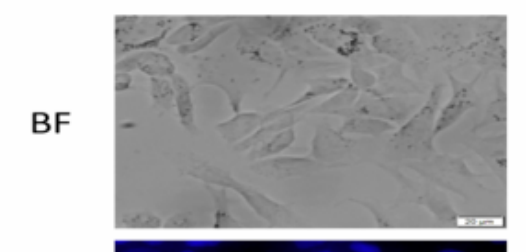

DAPI

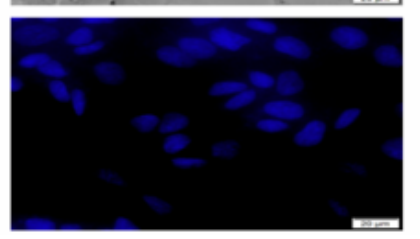

$\mathrm{Pg} 10 \mathrm{ug} / \mathrm{mL}$
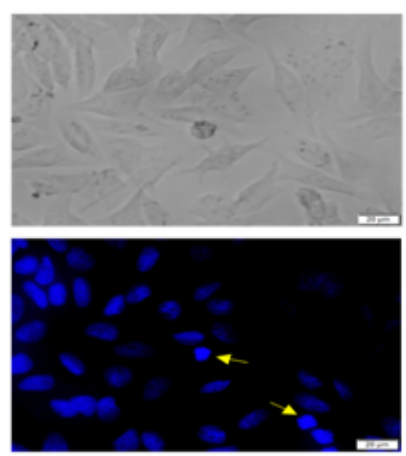

Pg 75 ug/mL
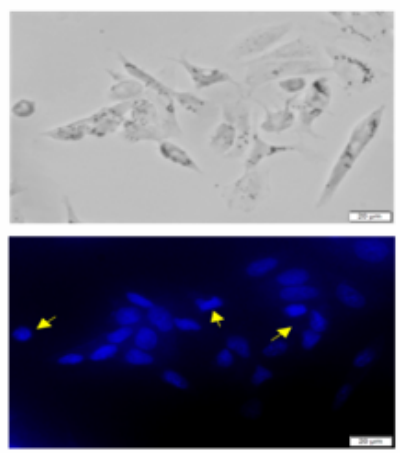

Pg 25 ug/mL
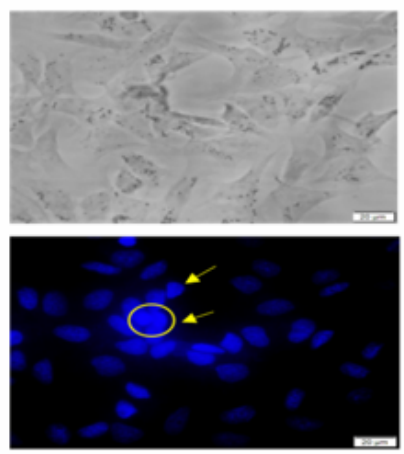

$\mathrm{Pg} 100 \mathrm{ug} / \mathrm{mL}$
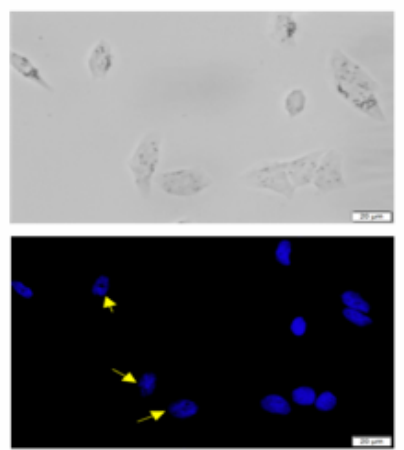

Pg 50 ug/mL
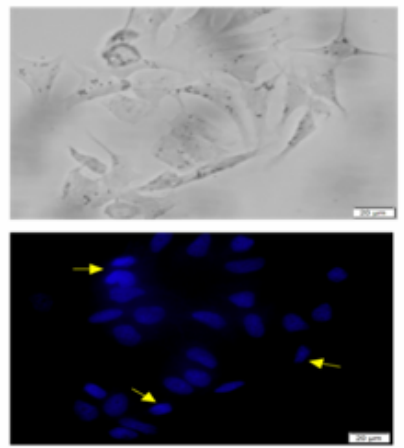

Pg 150 ug/mL
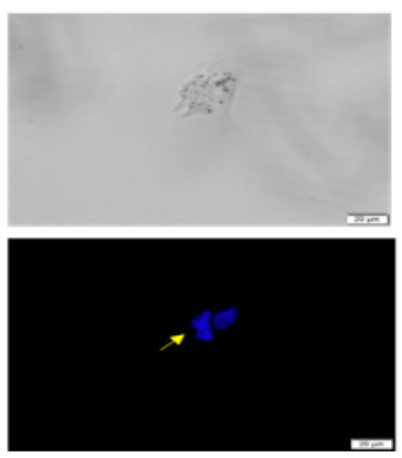

(a)

(b)

Figure 8

MCF7 human breast adenocarcinoma cells treated with Pg extract at different concentrations (a) $(10,25$, and 50 ug/mL) and (b) (75, 100, and 150 $\mu \mathrm{g} / \mathrm{mL}$ ) - for $72 \mathrm{~h}$ - BF = bright field microscopy; DAPI staining was performed for apoptotic morphological characteristics.

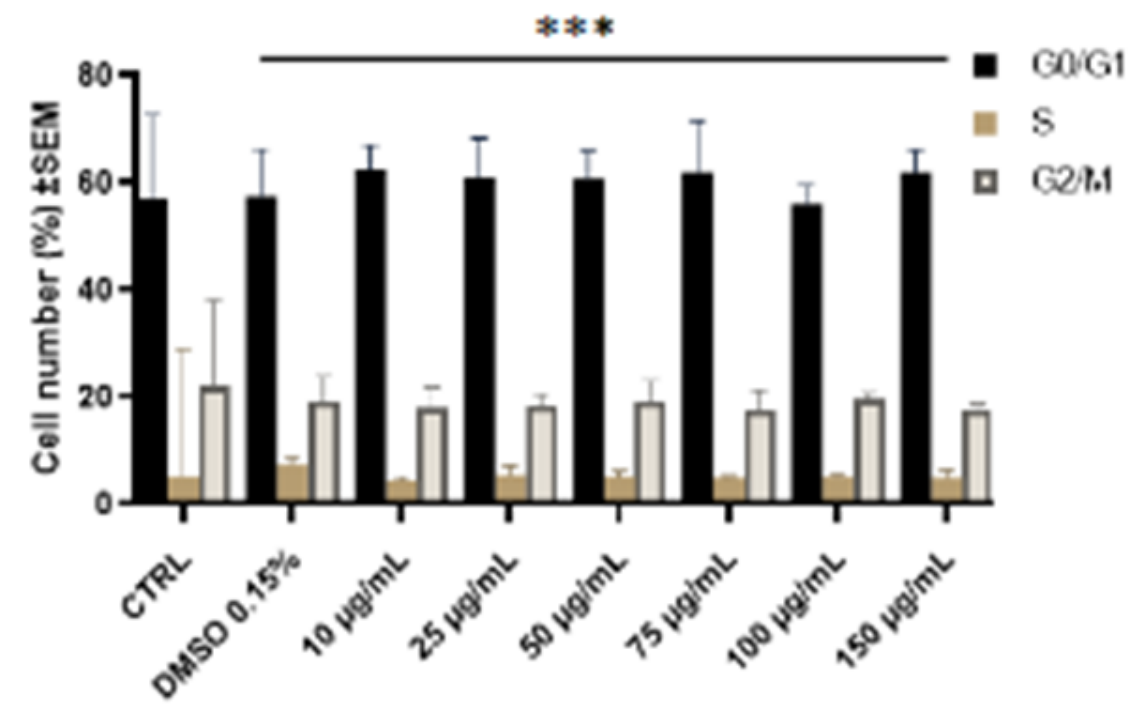

Figure 9

MCF7 human breast adenocarcinoma cell cycle arrest after stimulation with Pg (10, 25, 50, 75, 100 and $150 \mu \mathrm{g} / \mathrm{mL})$ on G0/G1; S and G2/M phases. The results are expressed as cell viability percentage (\%) related to the Control cells. Comparison among groups was made using One-way ANOVA test and Dunnett's multiple comparison post-test. (*** $p<0.0001$ vs. Control) 


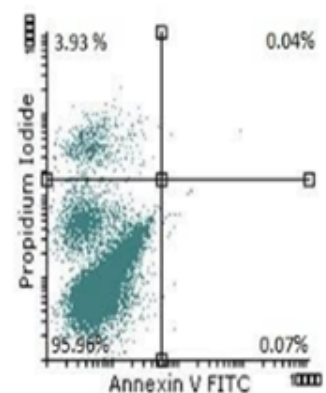

CTRL

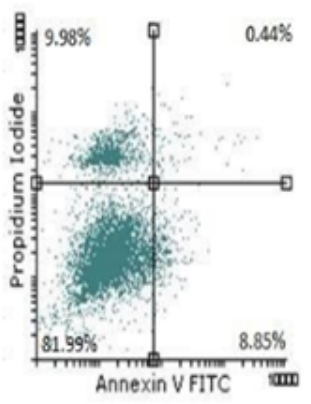

$50 \mu \mathrm{g} / \mathrm{mL}$
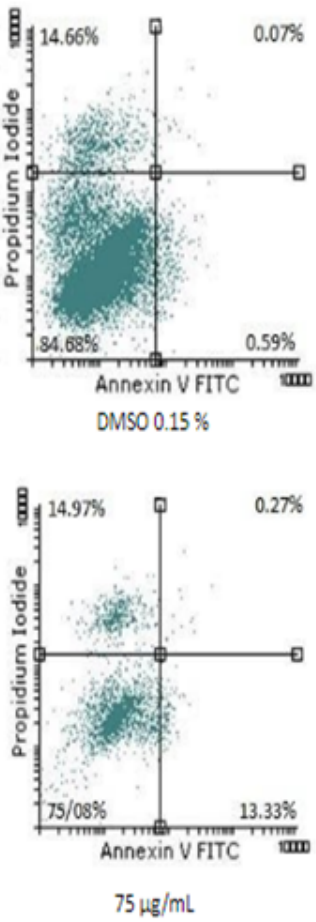

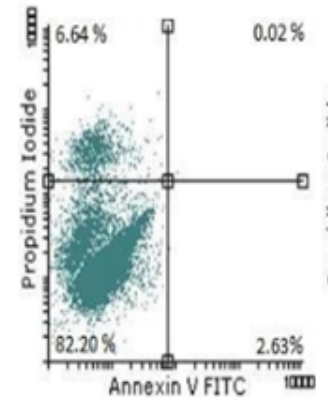

$10 \mu \mathrm{g} / \mathrm{mL}$
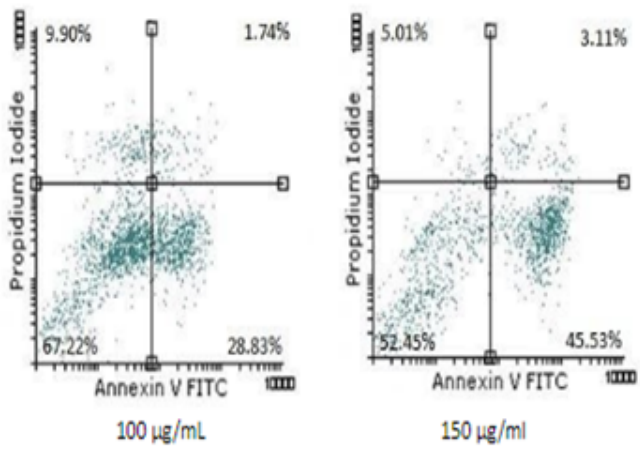

Figure 10

Representative histograms. Viability of MCF7 human breast cancer cell line using Annexin V/PI analysis.

\section{MCF-7 human breast cancer}

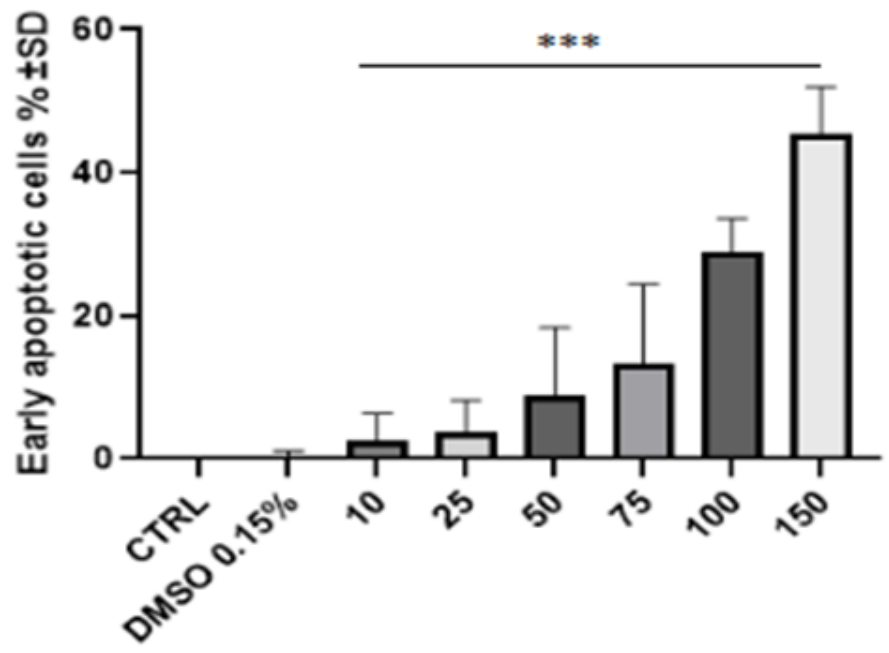

Concentration $(\mu \mathrm{g} / \mathrm{mL})$

Figure 11

The pro-apoptotic potential of Pg extract $(10,25,50,75,100$ and $150 \mu \mathrm{g} / \mathrm{mL})$ on MCF7 breast adenocarcinoma cells. The bar graphs are expressed as the percentage (\%) of early apoptotic cells related to control cells. Comparison among groups was made using One-way ANOVA test. ( $\star \star \star ~ p<$ 0.001 vs. Control). 


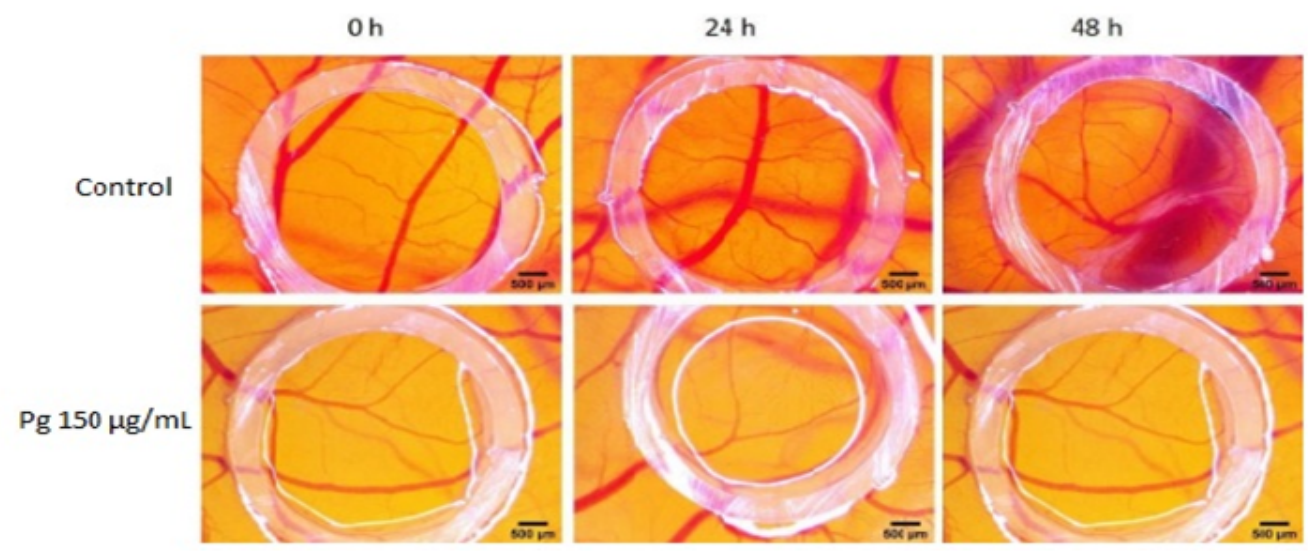

Figure 12

Effects of Pg extract on chorioallantoic membrane. Pg extract $(150 \mu \mathrm{g} / \mathrm{mL})$ and DMSO as control at $0 \mathrm{~h}, 24 \mathrm{~h}, 48 \mathrm{~h}$ after application; stereomicroscope images, scale bars, $500 \mu \mathrm{m}$.

Cell viability

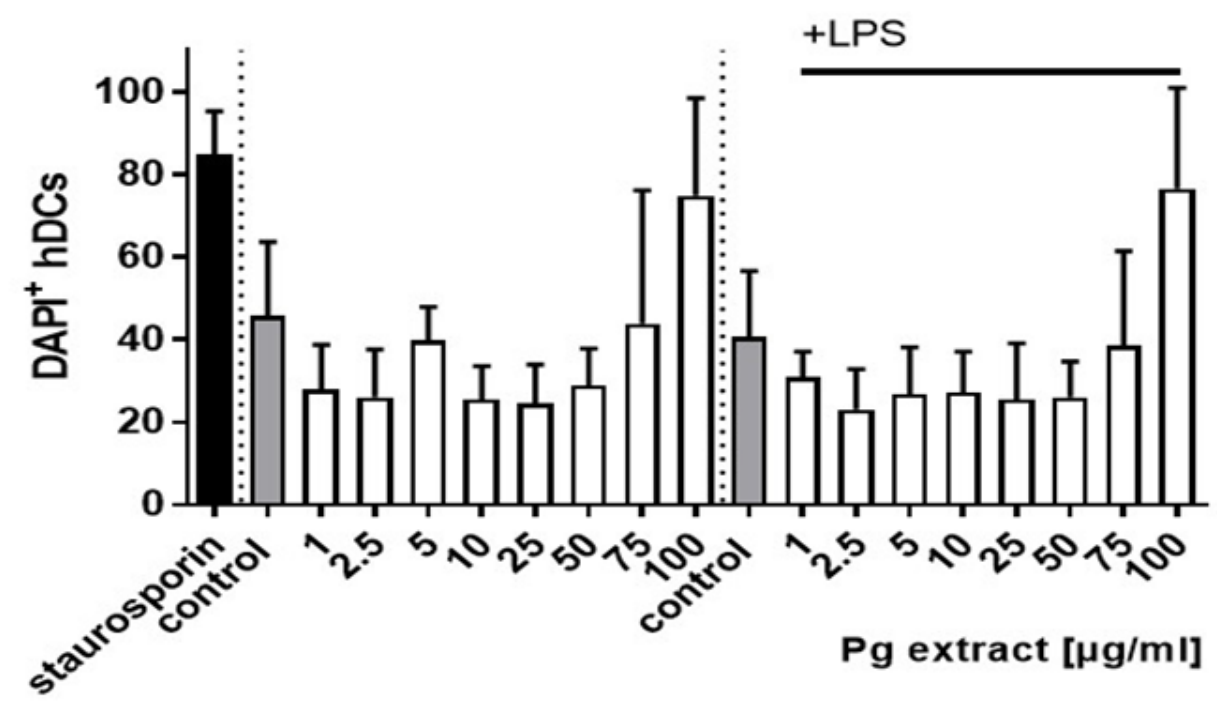

Figure 13

Effect of the Pg extract in different concentrations on the cell viability of naïve and inflammatory primary human dendritic cells $24 \mathrm{~h}$ after stimulation. Comparison among groups was made using One-way ANOVA test $(n=4)$.

\section{Late apoptosis}

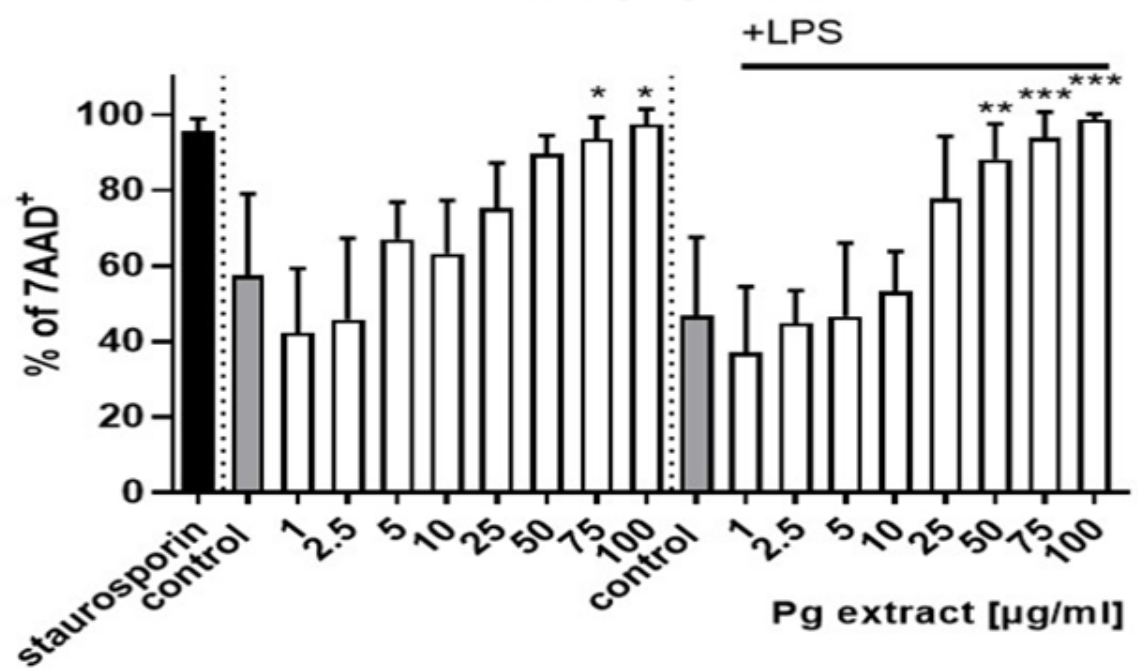


Figure 14

Induction of late apoptosis after stimulation with the Pg extract in different concentrations for $24 \mathrm{~h}$ of naïve and inflammatory primary human dendritic cells. Comparison among groups was made using One-way ANOVA test. $\left({ }^{\star} p<0.05,{ }^{* *} p<0.01, * \star * p<0.001\right.$ vs. Control).

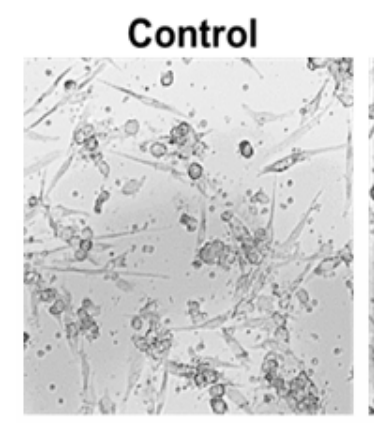

$\mathrm{Pg} 10 \mu \mathrm{g} / \mathrm{ml}$
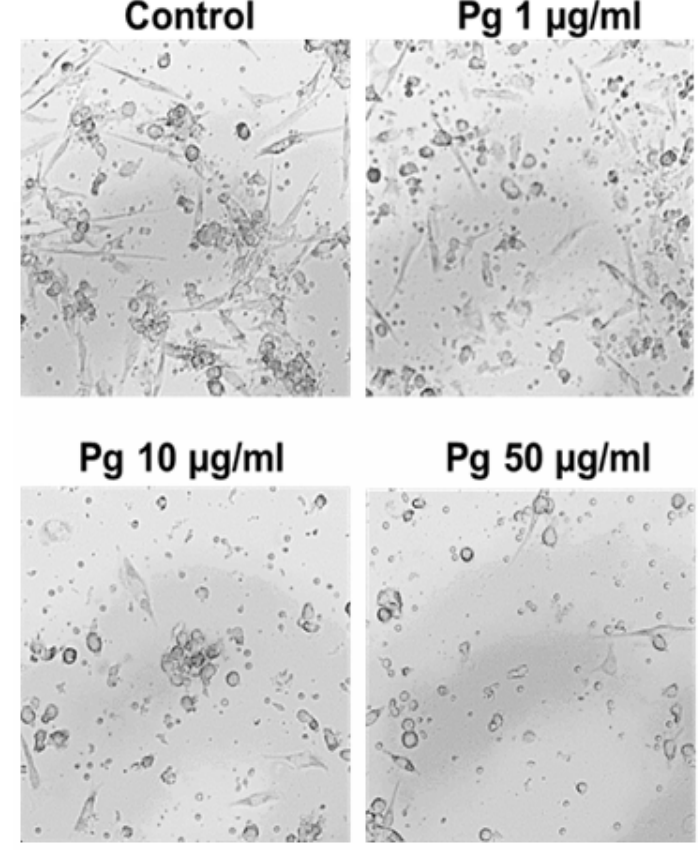

$\mathrm{Pg} 50 \mu \mathrm{g} / \mathrm{ml}$

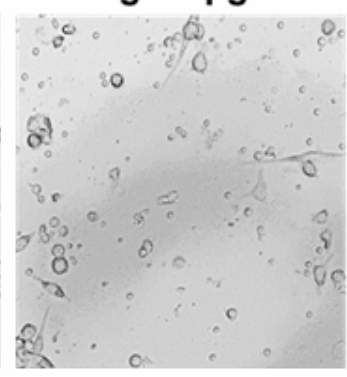

Pg $5 \mu \mathrm{g} / \mathrm{ml}$

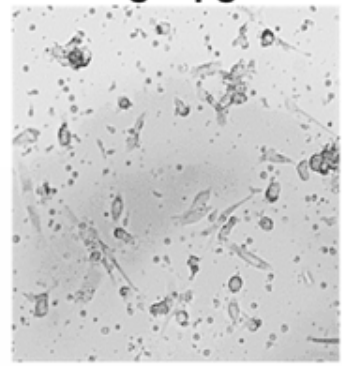

$\mathrm{Pg} 100 \mu \mathrm{g} / \mathrm{ml}$

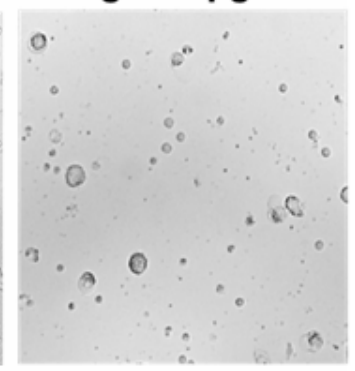

\section{Figure 15}

Light microscopic pictures of inflammatory human primary dendritic cells after $24 \mathrm{~h}$ of stimulation with the Pg-extract with indicated concentrations.

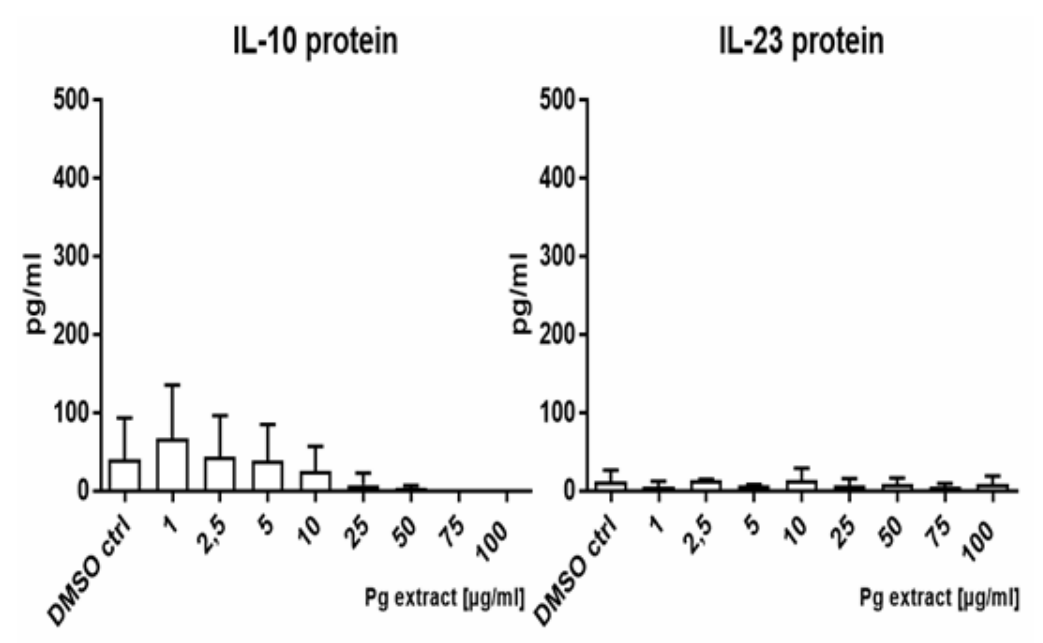

Figure 16

Effect of the Pg extract in different concentrations on the cytokine release (IL-10 and IL-23) of naïve primary human dendritic cells $24 \mathrm{~h}$ after stimulation. Comparison among groups was made using One-way ANOVA test. 

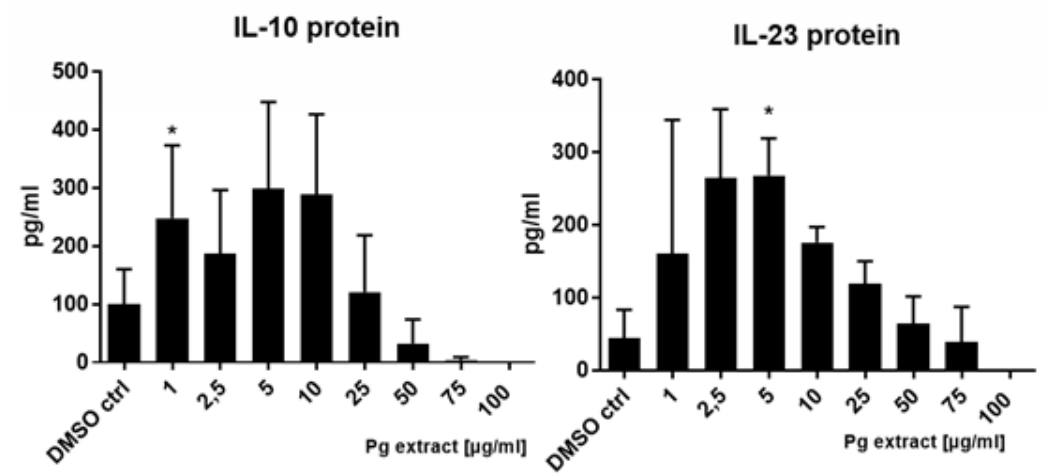

Figure 17

Effect of the Pg extract in different concentrations on the cytokine release (IL-10 and IL-23) of inflammatory primary human dendritic cells $24 \mathrm{~h}$ after stimulation. Comparison among groups was made using One-way ANOVA test. ( $\mathrm{p}<0.1$ vs. Control).

p19 mRNA

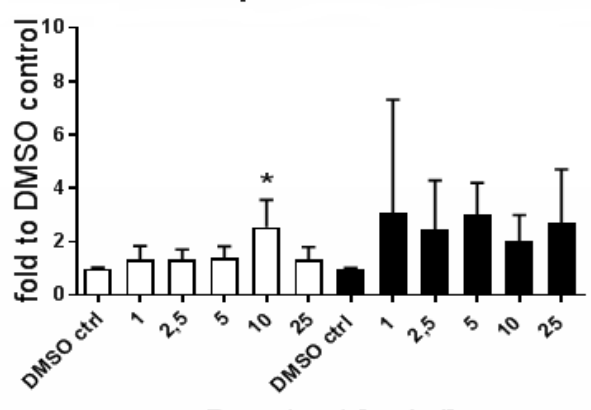

Pg extract $[\mu \mathrm{g} / \mathrm{ml}]$ p35 mRNA

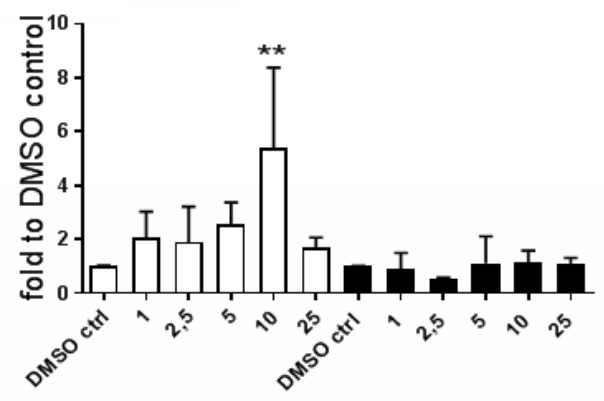

Pg extract $[\mu \mathrm{g} / \mathrm{ml}]$ p40 mRNA

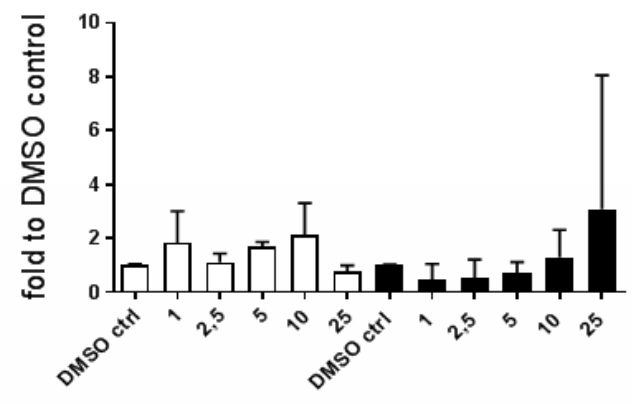

Pg extract $[\mu \mathrm{g} / \mathrm{ml}]$

Figure 18

Effect of the Pg extract in different concentrations on the mRNA expression of the cytokine subunits p19, p35 and p40 of naïve and inflammatory primary human dendritic cells $24 \mathrm{~h}$ after stimulation. Comparison among groups was made using One-way ANOVA test. (* $p<0.1 \mathrm{vs.} \mathrm{Control,} \mathrm{(**} p$ $<0.1$ vs. Control). 